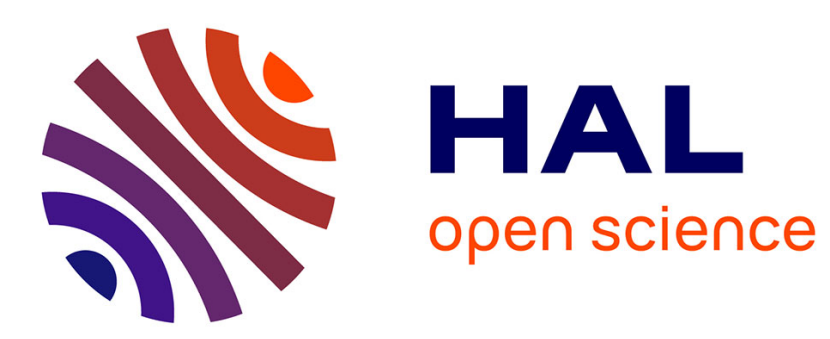

\title{
Development of a Nationwide Real-Time 3-D Wind and Reflectivity Radar Composite in France
}

Olivier Bousquet, Pierre Tabary

\section{To cite this version:}

Olivier Bousquet, Pierre Tabary. Development of a Nationwide Real-Time 3-D Wind and Reflectivity Radar Composite in France. Quarterly Journal of the Royal Meteorological Society, 2014, 140 (611625), pp.qj.2163. hal-00955745

\section{HAL Id: hal-00955745 https://hal.science/hal-00955745}

Submitted on 5 Mar 2014

HAL is a multi-disciplinary open access archive for the deposit and dissemination of scientific research documents, whether they are published or not. The documents may come from teaching and research institutions in France or abroad, or from public or private research centers.
L'archive ouverte pluridisciplinaire HAL, est destinée au dépôt et à la diffusion de documents scientifiques de niveau recherche, publiés ou non, émanant des établissements d'enseignement et de recherche français ou étrangers, des laboratoires publics ou privés. 


\title{
Development of a Nationwide Real-Time 3-D Wind and Reflectivity Radar Composite in France
}

\author{
Olivier Bousquet ${ }^{1}$ and Pierre Tabary
}

Météo France and CNRM-GAME, Toulouse, France

\author{
Submitted to \\ Quarterly Journal of the Royal Meteorological Society
}

August 2012

Revised December 2012 \& February 2013

\begin{abstract}
The ability to perform multiple-Doppler wind synthesis from operational weather radar systems on an operational basis has been investigated by the French Weather Service since 2006 using a (sub) network of 6 Doppler radars covering the greater Paris area. This analysis has been recently extended to the entire French radar network so as to implement a nationwide, three-dimensional reflectivity and wind field mosaic to be eventually delivered to forecasters and modelers, as well as automatic nowcasting systems for air traffic management purposes. In this composite analysis, data collected by all 24 radars of the French radar network are collected, pre-processed and combined in real-time at intervals of 15 minutes to retrieve the complete wind vector $(\mathrm{u}, \mathrm{v}, \mathrm{w})$ and reflectivity fields at a horizontal resolution of $2.5 \mathrm{~km}$ within a domain of approximately $1000 \times 1000 \times 12 \mathrm{~km}^{3}$. In order to illustrate the performance of this new product, examples of 3-D wind and reflectivity outputs produced during the passage of two significant weather events are presented: the extratropical storm Klaus, which struck France on 24 January 2009 with hurricane force gusts, and a typical orographic high impact precipitation event that developed on 21 October 2009. The evaluation of real-time radar outputs against operational analyses attests of the consistency of the retrieved wind fields.
\end{abstract}

\footnotetext{
${ }^{1}$ Corresponding author: Dr Olivier Bousquet, CNRM-GAME, Météo-France, 42 Av. G. Coriolis, 31057 Toulouse, France. E-mail: olivier.bousquet@meteo.fr
} 


\section{Introduction}

The ability to retrieve three-dimensional reflectivity and wind vector fields from operational radar networks has a potentially wide-ranging impact on a variety of meteorological research and operational meteorological applications, but many challenges have yet to be taken up in order to produce consistent and reliable 3D radar mosaics in a fully operational framework. This includes fast and efficient data transmission, operationally-oriented pre-processing methods for unfolding, synchronization, clutter suppression, and interpolation of radar data, high radar network density, as well as computationally efficient mosaicking and wind synthesis algorithms, just to name a few.

Thanks to recent advances in radar signal processing and radar data analysis, most of these challenges are fortunately about to be solved: current data compression techniques allow for rapid and effective transmission of radar observations to end users; efficient interpolation and mosaicking schemes have been proposed and tested in an operational framework (e.g. Zhang et al. 2005, Gao 2009); unfolding algorithms specifically designed for operational purposes have been developed (e.g. Zhang and Whang 2006, He et al. 2012) and multiple pulse repetition time (PRT) Doppler schemes, which allow extending the Nyquist velocity significantly, are implemented on operational radar systems (Torres et al. 2004, Tabary et al. 2005, 2006); computationally effective multiple-Doppler wind retrieval algorithms have been proposed and tested in operational frameworks (Dolan and Rutledge 2007, Bousquet et al. 2008), and last but not least, gap filling radars have started to be deployed within operational networks to mitigate gaps in radar coverage and increase the ability to study and forecast localized, high risk, precipitation events (McLaughlin et al. 2009, Rude et al. 2012, Westrelin et al. 2012).

The capability to perform multiple-Doppler wind retrieval in an operational framework has been recently evaluated by the French Weather Service in the course of an upgrade program aiming to introduce Doppler and dual-polarization technologies within the French radar network. Starting in November 2006, real-time multiple-Doppler wind fields have been produced routinely every 15 minutes during 2 years within a 320x320 km² domain centered on Paris city. The evaluation of wind fields synthesized in this framework was carried out from observations collected in a variety of weather situations including low-level cyclones, 
frontal systems and squall lines (Bousquet et al. 2007, 2008a). Retrieved winds were proved very realistic and have been found reliable enough to be used for research applications (mesoscale meteorology, statistical analysis) and numerical model verification (Bousquet et al. 2008b). In order to prepare the field phase of the international Hydrological Cycle in the Mediterranean Experiment $\left(\mathrm{HyMeX}^{2}\right)$, which will be conducted in 2012, this analysis has been later tested in regions of complex terrain located in southern France (Bousquet 2009). The extension of this analysis to mountainous areas is an important step to improve our understanding of orographic precipitation as well as to evaluate more accurately numerical model performance in these poorly instrumented regions often prone to flash flooding. This achievement moreover established that operational, real-time, wind retrieval could potentially be achieved over the whole French territory - ground elevation exceeds $500 \mathrm{~m}$ over $\sim 1$ fifth of mainland France - which was the initial objective of the French Weather Service when starting the 2006 Paris experiment.

The ability to retrieve 3-D wind fields from a larger network of Doppler radar has been recently investigated by Park and Lee (2009), who used all 18 Doppler radars of the South Korean operational radar network to achieve wind retrieval over the Korean peninsula at a horizontal resolution of $5 \mathrm{~km}$. This study demonstrated that combining data from a large number of instruments was technically feasible and established the potential usefulness of such radar product for atmospheric research and forecasting purposes. Park and Lee's analysis was, however, performed in "research mode" and was only restricted to two representative cases due to the substantial, time-consuming, manual editing required to pre-process radar observations.

The present study elaborates on Park and Lee's work by presenting technical solutions relied upon in France to consistently process considerable amount of radar data fast enough so that radar-derived outputs could be potentially delivered to users in real-time. This achievement, through the size of the retrieval domain $\left(1000 \mathrm{x} 1000 \mathrm{~km}^{2}\right)$, the number of Doppler radars (24) involved in the analysis, and the fact that retrieved three-dimensional winds rely exclusively on an operational infrastructure, represents an unprecedented breakthrough in operational weather radar applications. Together with data assimilation

\footnotetext{
${ }^{2}$ Information about the HyMeX research programme is available at http://www.hymex.org/
} 
(Montmerle and Faccani 2009) and the ongoing development of a national low-level wind shear mosaic (Augros et al. 2013), this technical development is the third advanced radar product based upon the use of operational radial velocity observations developed by the French Weather Service.

After a brief description of the current state of the French radar network, Section 2 recalls the principle of the analysis described in Bousquet et al. (2008a), with emphasis on technical modifications allowing its application at the country scale. In order to illustrate the performance of this analysis, section 3 presents realtime radar outputs produced during high impact weather events that hit France in 2009: The extratropical storm Klaus, referred to as the storm of the decade by many European forecasters, which struck France with hurricane strength winds on 24 January, and a heavy orographic precipitation event that occurred over the Massif Central Mountains on 21 October. Retrieved wind fields are evaluated in Section 3 through comparisons against operational model analyses and surface data. Section 4 concludes with a short discussion on anticipated applications and planned improvements.

\section{Technical considerations}

\section{a) Characteristics of the French radar network}

The French metropolitan operational radar network is composed of 24 weather radars covering about 95 $\%$ of continental France with radar spacings ranging from $\sim 180 \mathrm{~km}$ in the northern part of the country down to less than $60 \mathrm{~km}$ in Southeastern France (Fig. 1). The French radar network, called Application Radar à la Météorologie Infra-Synoptique (ARAMIS), is composed of 5 different models of radars ranging from 25year old facilities, with limited duty cycle and scanning capabilities, to brand new, state of the art, dualpolarimetric radar systems. All systems are however equipped with the same radar processor, which allows producing harmonized products despite their different technical characteristics, at least from a radar processor perspective. Note that Météo France also operates nine additional radars that are not considered in this paper: seven radars overseas and 2 gap filling X-band radars deployed in the Alps in the frame of the RHYTMME project (Westrelin et al. 2012, Frasier et al. 2012, Beck and Bousquet 2012). 
Doppler capabilities have been introduced in 2002 in the frame of a 6-year duration upgrade program, whose objectives were to modernize the network and to fill some gaps in the radar coverage. Nowadays all ARAMIS weather radar systems are Doppler-ized and ten of them have also been upgraded to dualpolarimetric capabilities. All radars are equipped with the triple pulse rise time (PRT) Doppler scheme proposed by Tabary et al. (2006) to address the mitigation of range and velocity ambiguities (Zrnic and Mahapatra 1985). The particularity of this scheme, which yields an extended Nyquist velocity of $60 \mathrm{~m} \mathrm{~s}^{-1}$ up to a range of $\sim 250 \mathrm{~km}$, is that the three interleaved frequencies are rather low $(379,321$, and $305 \mathrm{~Hz})$. This allows this scheme to be implemented on old and new radars as well as to get rid of potential second trip returns. The drawback, however, is that the dealiasing success rate, which averages $\sim 90 \%$, could sometimes decrease significantly due to the closeness of the 3 pulse repetition frequencies (PRF). This is particularly true in low signal-to-noise ratio (such as in clear air situations) or large spectrum width (such as in intense convection) conditions. A solution to mitigate these issues, which has been investigated by Augros and Tabary (2009), is to increase the values of the PRFs. A modified scheme allowing for a mean PRF value of $471 \mathrm{~Hz}$ instead of the current $335 \mathrm{~Hz}$ value is being progressively implemented on all French radar systems.

All radars perform a complete volume scan in 15 minutes according to the volume coverage patterns (VCP) demonstrated in Table 1 . The scanning strategies are radar specific and comprise three 5 minute cycles that are repeated every 15 minutes (supercycle). The volume coverage patterns have been essentially designed for hydrological purposes and consist in a few low-elevation scans repeated every 5 minutes that are usually interlaced with higher elevation scans.

\section{b) Data analysis}

Reflectivity and radial velocity observations from all operational radars are concentrated at the national center in Toulouse and processed every 15 minutes (radar sweeps used in the current analysis are highlighted in Table 1). Data consist in Plan Position Indicators (PPI) projected on a Cartesian grid of $512 \mathrm{~km}$ x $512 \mathrm{~km}$ with a resolution of $1 \mathrm{~km}^{2}$. These data are already used operationally for several applications including Velocity Azimuth Display (VAD) analysis (Browning and Wexler 1968), quantitative precipitation estimates 
(Tabary et al. 2011) and data assimilation purposes (Montmerle and Faccani 2009). On conventional (i.e. non polarimetric) radars, spurious reflectivity echoes are removed by the mean of a threshold on the pulse-topulse fluctuation of the reflectivity following Sugier et al. (2002). On polarimetric radars, the fuzzy logic algorithm proposed by Gourley et al. (2007) is currently relied upon to separate precipitating from nonprecipitating echoes. A $5 \times 5 \mathrm{~km}^{2}$ median filter is then applied to radial velocity measurements to discard potential spurious velocities resulting from dealiasing failures (Tabary et al. 2006).

Once pre-processed, data are synchronized with respect to the ending time of the considered 15 minute supercycle period to account for the non-simultaneity of the measurements following the approach of Tuttle and Foote (1990). Reflectivity and velocity observations from all radars are then ingested in the operational version of the variational Multiple-Doppler Synthesis and Continuity Adjustment Technique (MUSCAT; Bousquet et al. 2008a). Data are interpolated into a Cartesian grid using a fixed horizontal influence radius of the Cressman weighting function $R_{H}$ of $3 \mathrm{~km}$ and a variable vertical radius of influence $R_{V}$ equal to $1^{\circ}$ (beamwidth of the ARAMIS radars). This configuration allows $R_{V}$ to vary as a function of range such that the search for data points extends farther out at long range compared to short range. This allows to account for the loss of resolution at long range resulting from beam broadening. Radar data can be interpolated into either "French" Lambert coordinates ("Lambert II étendu”) or polar-stereographic projection. The current retrieval domain measures $1000 \mathrm{~km}$ x $1000 \mathrm{~km}$ x $12 \mathrm{~km}$ and encompasses the whole country but Corsica island. The vertical resolution is set to $500 \mathrm{~m}$, while the horizontal resolution is set to $2.5 \mathrm{~km}$ so as to be consistent with smoothing effects inherent to the finite beamwidth.

The detailed radar coverage resulting from the use of the above-mentioned $R_{H}$ and $R_{V}$ Cressman weighting functions is shown in Fig. 2 (see caption for more details about the construction of these maps). The coverage is fairly limited near the ground due to the wide spacing of radars and beam blocking by terrain (Fig 2a-b), but it nevertheless quickly improves with height. Indeed, between 2 and 10 km AMSL ${ }^{*}$ (Figs. 2c) about $90 \%$ of the country is covered by at least 2 radars. Multiple-Doppler coverage ( 3 radars or more) is maximized between 2.5 and $9 \mathrm{~km}$ altitude, where $\sim 80 \%$ of mainland France is covered by at least 3 radars. In

\footnotetext{
* In the following all heights are given Above Mean Sea Level
} 
regions sampled simultaneously by two or more radars, one can estimate the 3-D wind velocity using overdetermined dual-Doppler synthesis methods such as MUSCAT (Bousquet and Chong 1998) or other techniques based upon the utilization of the equation of mass continuity (Armijo 1969, Ray et al. 1980). The availability of three or more coordinated Doppler radars allows to reduce the error variance and to achieve more accurate determination of wind fields (Ray and Wagner 1976, Davies-jones 1970). Within overlapping areas, reflectivity data from all individual radars influencing a given grid point are also merged using a weighted mean procedure. The weight depends on the distance $d$ between the considered grid point and the radar location. It decreases monotonically with range such that observations at far range receive smaller weights than those located near the radar. The weighting function is given by:

$$
W=\left(R^{2}-d^{2}\right) /\left(R^{2}+d^{2}\right) \text {, where } R \text { is arbitrary fixed to } 300 \mathrm{~km}
$$

More information about the impact of weighting functions on reflectivity compositing procedures can be found in Zhang et al. (2005).

In order to comply with future operational time requirements, the retrieval domain is divided into 4 overlapping sub-domains, each measuring $520 \mathrm{~km}$ x $520 \mathrm{~km}$ x $12 \mathrm{~km}$. Working with sub-domains allows faster wind synthesis, especially when large portions of the country are filled up with precipitation. A bilinear interpolation is used to retrieve the wind and reflectivity fields in overlapping areas and an a posteriori upward integration of the air mass continuity equation is performed to ensure that the composite wind field strictly verifies the continuity equation. Note that in MUSCAT, the three components $(\mathrm{u}, \mathrm{v}, \mathrm{w})$ of the wind field are solved simultaneously, which allows to overcome potential errors resulting from the use of an iterative solution. The reader is referred to Bousquet and Chong (1998) and Bousquet et al. (2008a) for a detailed description of this formalism and for an evaluation of its performance.

As of today, retrieved reflectivity and wind fields are respectively available 5 and 7 minutes after the completion of a given 15 minute supercycle (the composite 3D reflectivity field is created prior to the wind synthesis so as to be available faster to forecasters). It takes approximately 3 minutes to centralize all PPIs in 
Toulouse (where the main meteorological center is located), $\sim 1$ minute to process and interpolate the raw data, and $\sim 3$ minutes to synthesize the wind and reflectivity fields.

\section{Examples of real-time analyses}

The proposed approach had been running almost continuously since September 2008 and numerous precipitation events have been examined within each season. This section presents the results from two representative cases that struck France in 2009: the extratropical cyclone "Klaus" that occurred on 24 January and an orographic precipitation event that occurred on 21 October in the Massif Central region.

a) The Klaus storm

\section{1) Overview}

On 24 January 2009, the extratropical cyclone "Klaus" made landfall over southwestern Europe with hurricane force gusts, causing widespread damage and ten's of fatalities across France and Spain. This weather event was the most intense and damaging storm to affect Western Europe since the infamous extratropical cyclones "Lothar" (Wernli et al., 2002) and "Martin" in 1999. The most damaging effects due to "Klaus" occurred in southern France where millions of homes and commercial properties experienced power cuts and heavy damages due to falling trees. In Northern Spain and Southwestern France some of the most productive European forests were profoundly impacted by the storm and will take decades to recover. The intensity, and to some extent the timing, of this storm was relatively well forecasted by the models. In France the highest warning level ("vigilance rouge") for winds was released some 12 hours prior to the cyclone landfall.

Klaus formed west of the Azores islands on 23 January 2008 near 00 UTC. The life cycle of this system approximately follows the conceptual model proposed by Shapiro and Keyser (SK, 1990). It is characterized by an explosive intensification period, during which the sea level pressure (SLP) at the cyclone center deepened by $\sim 36 \mathrm{hPa}$ in 24 hours, ending up with a warm seclusion phase and a rapid decay. The SLP minimum $(964 \mathrm{hPa})$ was attained at $00 \mathrm{UTC}, 24$ January, as the center of the low-level vortex was located 400 kilometers off the French coasts (Fig. 3a). This time more or less marked the beginning of the 
occlusion/seclusion phase, which lasted for about 8 to 10 hours. The corresponding surface analysis (Fig. 4a) shows a warm frontal zone to the North of the cyclone center and a cold front extending far southward across the Pyrenees and Northern Spain. According to satellite images the storm was elongated in the west-east direction along the warm front, which is in good agreement with the SK model theory (Schultz et al. 1998). Klaus made landfall slightly before 6 UTC on 24 January (Fig. 3b) with a minimum pressure of $\sim 967 \mathrm{hPa}$ (Fig. 4b). After landfall, the system continued to progress eastward at a mean speed of $15 \mathrm{~ms}^{-1}$ and reached Italy near 18UTC. At this time the system appeared to be much less organized and the associated minimum pressure has already increased to $988 \mathrm{hPa}$ (Fig. 4b).

Unprecedented surface wind speeds were measured during the passage of the storm over Southern France and Northern Spain. Maximum surface winds occurred in a region located approximately 300-350 km south of the cyclone center, along a $100 \mathrm{~km}$ swath oriented in a direction parallel to the cyclone trajectory (Fig. 4b). In France, wind gusts peaked at $\sim 184 \mathrm{kmh}^{-1}$ near Opoul (Fig. 1), a speed that corresponds to category 3 hurricane winds on the Saffir-Simpson scale. The Momuy radar facility (Fig. 1) was forced to cease operations near 05UTC due to heavy wind damages, but velocity data collected just prior to the radar failure show radial wind values in excess of $60 \mathrm{~ms}^{-1}\left(216 \mathrm{kmh}^{-1}\right)$ at $2000 \mathrm{~m} \mathrm{MSL}$ and $~ 45 \mathrm{~ms}^{-1}\left(160 \mathrm{kmh}^{-1}\right)$ above the ground.

\section{2) Radar-derived wind and reflectivity fields}

Observations collected between 03 and 12 UTC on 24 January 2009 are relied upon to assess the consistency and potential value of real-time wind and reflectivity composites retrieved during the propagation of Klaus over the French territory. At this time the French radar network was not yet completely Doppler-ized (see Table 1) resulting in some gaps in the dual-Doppler radar coverage over northwestern and southern France. Despite this limitation, real-time 3-D wind and reflectivity mosaics created during the passage of this exceptional storm over the French radar network provide unprecedented observations of the precipitation and wind structures associated with "bomb like" extratropical cyclone. 
Figures 5 and 6 present horizontal cross-sections of multiple-Doppler wind and reflectivity data at a height of $2 \mathrm{~km}$ and different stages of the storm evolution. At 3 UTC (Fig. 5a-b), i.e. three hours before landfall, most of the country was already covered by weak to moderate precipitation. Heaviest rainfalls occur approximately $300-400 \mathrm{~km}$ ahead of the cyclone center along a SW-to-NE oriented rainband that marks the location of the cold front. Another area of intense precipitation associated with the cloud head (Browning 1999) could be also identified farther west. Both regions of intense precipitation were separated by a region of weak precipitation corresponding to the dry identified in the satellite imagery (Fig.3a). At this time, relatively intense winds in the range of $25-30 \mathrm{~ms}^{-1}$ could already be observed over southeastern France (east of the cold front) and within the cloud head.

Klaus made landfall at $\sim 6$ UTC near Treillières (Fig. 5c-d). The cyclone center, characterized by a closed circulation of $\sim 350 \mathrm{~km}$ in diameter, can be identified in Fig $5 \mathrm{c}$. At that time strong winds reaching up to 50 $\mathrm{ms}^{-1}$ have already encroached deeply over land. A patch of particularly intense winds could be observed on each side of the dry slot, approximately $400 \mathrm{~km}$ south of the storm center. The north-south location of this area of strong winds agrees well with surface observations (Fig. 4b). Several thin rainbands can also be observed within the cloud head, to the west of the wind maximum. Those precipitation structures, which have already been described by Browning (2004), suggest the presence of mesoscale slantwise circulations that may have played a significant role in reinforcing the winds close to the ground. The evolution of the storm after landfall is shown in Fig. 6. The region of strong winds stretched out along an axis paralleling the Pyrenees Mountains and slowly progressed eastwards. Strong winds persist at all times during the propagation of the storm across France. At 12UTC, a wind maximum of $\sim 55 \mathrm{~ms}^{-1}$ could be observed near Opoul ( $x \sim 600 \mathrm{~km}, y \sim 150 \mathrm{~km}$ ) in good agreement with surface observations (Fig. 4b).

As already discussed in Bousquet et al. (2008a), the validation of operational multiple-Doppler wind data is a particularly challenging task due to the lack of available verification datasets at the space-time resolution achieved by Doppler radars. In Bousquet et al. (2007) and (2008a) wind profiler data and simulated radar observations have been respectively relied upon to evaluate quantitatively the consistency of the retrieved winds within a 400x400 km² experimental domain located in Northern France. Results of these tests have demonstrated that it was possible to achieve a precise mapping of the kinematic structure of rain events 
despite large baselines and limited scanning strategies that characterize the French radar network. In order to evaluate the consistency of the retrieved wind fields over the larger domain considered in this study, radarderived wind fields are this time compared to model winds analyzed by the French operational numerical weather prediction system ALADIN (Aire Limitée Adaptation Dynamique Développement International; Radnóti et al. 1995).

Such comparison for a height of $1.5 \mathrm{~km}$ MSL and at 6 UTC is shown in Fig. 7. Overall, the observed and analyzed midlevel flows match relatively well both in terms of magnitude and direction. The position and size of the vortex is similar in both datasets, which attests of the good agreement between the model and radar wind fields. Some discrepancies can however be noticed in the vicinity of the cold front (insert 2) where radar-derived winds indicate a well-defined shift in wind direction that appears less marked in the analyzed wind field. The model also produces a prominent meridional wind component $\sim 500 \mathrm{~km}$ to the East of the cyclone center (insert 1) that does not exist in the radar-derived wind field. This pronounced southerly component was missing in all multiple Doppler radar analyses produced between 4 and 8 UTC and could not be identified in raw Doppler velocity data either (not shown). The latter point suggests an error in the model analysis rather than in the wind retrieval.

Although multiple-Doppler winds cannot be retrieved immediately above the ground, a comparison between reconstructed low-level winds and surface wind data within the patch of high winds was performed to investigate a possible complementary relationship between the two datasets (see Figs. 5 and 6 for comparison areas). At $1 \mathrm{~km} \mathrm{MSL}$, which is the lowest level where multiple-Doppler winds can be realistically retrieved, one noted a good agreement between the radar-derived winds and wind gusts measured at the surface. The difference between radar-derived and surface winds measured by 50 surface stations over a 7 hour period averages around $0.5 \mathrm{~ms}^{-1}$ with a RMS of $\sim 7.3 \mathrm{~ms}^{-1}$. Such consistency is not surprising since most forecasters consider as a rule of thumb that maximum surface wind gusts in cold air are generally in good accordance to mean wind speed at 900-925 hPa. Although the relation between winds a 
kilometer or so above the ground and the strength of the surface wind gusts does strongly depend on the static stability, this result suggests that low-level multiple-Doppler winds might nevertheless be used to infer some properties of the surface winds during winter storms. A long term analysis is nevertheless obviously needed in order to confirm this hypothesis.

This first case study illustrates the benefits of both qualitative and, to some extent, quantitative information that could potentially be inferred from the examination of radar-derived wind and reflectivity fields. Indeed the availability of complete 3D wind vector fields over France every 15 minutes during the passage of Klaus would have been a practical tool to estimate the location of potentially hazardous wind gusts and to possibly trigger(or cancel) alerts based on the eastward propagation of the swath of strong winds.

b) Cevenol precipitation event

1) Overview of the 21 October 2009 weather event

During fall and winter seasons the Cevennes area is often affected by flash-flooding events resulting from the formation of intense mesoscale convective systems along the south-eastern flank of the Massif Central Mountains. The precipitation intensity in this region being very high, these weather events can generate considerable amount of precipitation in short periods of time. A famous example of such systems is the 8 September 2002 case (Delrieu et al. 2005) during which $\sim 800 \mathrm{~mm}$ of rain fell down in less than 24 hours near Nîmes (Gard department) causing several fatalities and damage amount of more than 1 billion $€$. Better observations of the dynamical and microphysical processes at play during these so-called "Cevenol" precipitation events are critical to assess the validity and accuracy of model forecasts and to design more effective warning procedures. In this respect, the availability of real-time multiple-Doppler wind and reflectivity data in the Cevennes area every 15 minutes potentially represent a valuable tool for both researchers and forecasters. Examples of wind and reflectivity fields produced during a severe precipitation event that occurred in the Nimes area on 21 October 2009 are presented hereafter. This storm locally 
produced rainfall accumulation in excess of $200 \mathrm{~mm}$ in about 24 hours and led to significant damage in the Gard and Herault departments where several small cities were partly flooded.

The $500 \mathrm{hPa}$ and surface analyses at $12 \mathrm{UTC}, 21$ October 2009, are displayed in Fig. 8. The $500 \mathrm{hPa}$ analysis (Fig. 8a) show an upper-level cold low centered west of the British Islands with an associated eastward propagating trough extending southward toward Spain. This synoptic pattern generates a mid-toupper level S'ly to SW'ly flow over France and a low-level S'ly to SE'ly flow over the Mediterranean Sea. The latter is advecting warm and moist air masses toward the coast. The corresponding low-level analysis (Fig. 8b) shows a surface low centered near Ireland and a cold front extending across France. Relatively strong winds develop ahead of the cold front. The 24-h precipitation field (Fig. 8c) shows a pronounced maximum along the foothills of the Massif Central. The local maximum was observed over the slopes, in the city of Villefort (Lozere department) where $226 \mathrm{~mm}$ of precipitation was recorded in slightly more than 24 hours.

\section{2) Radar-derived wind and reflectivity fields}

Figure 9 presents 6-hourly multiple-Doppler analysis of radar data starting at 0UTC, 21 October at a height of $2000 \mathrm{~m}$ AMSL. All radars of the French radar network performed nominally on this day except for the Abbeville radar (in northern France) that was down due to routine maintenance operations. Also note that the Bordeaux and Grezes radars (Fig. 1) were not yet upgraded to Doppler capabilities at this time.

At 00 UTC (Fig. 9a) the retrieved circulation at $2 \mathrm{~km}$ exhibits a south-to-southwesterly component of $\sim 15 \mathrm{~ms}^{-1}$ associated with a broad ( $200 \mathrm{~km}$ wide), eastward propagating, frontal rainband extending meridionally over the entire French territory. Some variations in the retrieved wind direction likely associated with the oscillations of the cold front can be noticed in areas of intense precipitation in SW France. The wind transition at the front is sharp with moderate SW'ly winds $\left(\sim 15 \mathrm{~ms}^{-1}\right)$ before and weaker S'ly flow $\left(\sim 5-10 \mathrm{~ms}^{-1}\right)$ after. Farther east, a strong $\left(\sim 25 \mathrm{~m}^{-\mathrm{s}^{-1}}\right)$ SE'ly flow can be observed over the Massif Central and Gulf of Lion areas at a height of $2 \mathrm{~km}$. This SE'ly flow, which advects warm and moist air masses from the Mediterranean Sea toward the coast, impinges on the Massif Central Mountains and is 
responsible for the more cellular character of precipitation over the southern flank of the massif. The convective activity in the latter area increased significantly in the following 6 hours (Fig. 9b). The southeasterly flow intensified to reach up to $30 \mathrm{~ms}^{-1}$ and convective cells eventually aggregated into an elongated, stationary, mesoscale convective system (MCS) banked up along the flank of the mountains. Precipitation also intensified over the western slopes of the Massif Central partly as a result of interactions between the SW'ly flow and underlying terrain, but was also possibly enhanced by the confluent SE'ly and SW'ly flows meeting in this area. The front did not seem to be blocked or delayed by the Massif Central Mountains and continued its eastwards propagation at a mean speed of $7.5 \mathrm{~ms}^{-1}$ to reach the eastern flank of the Massif Central near 12 UTC (Fig. 9c). The frontal rainband then merged with the stationary MCS and convective precipitation was displaced slightly eastwards, over the Rhone valley. At 18 UTC (Fig. 9d), convective precipitation over the Rhone valley and the Massif Central has disappeared.

Information about the vertical structure of precipitation can be inferred from Fig. 10, which presents meridional vertical cross-sections of the retrieved 3D composite reflectivity pattern along a $1000 \mathrm{~km}$ line ranging from the Golf of Lion, in the Mediterranean Sea, to southern Belgium (cf. north-south line indicating horizontal projection of these sections in Fig. 9c and 9d). These cross-sections provide a unique picture of the structure and evolution of precipitation over the entire country that can be used to identify regions of intense rainfall, as well as to discriminate between heavy and light precipitation intensity. At 12 UTC (Fig. 10a) and 18 UTC (Fig. 10b) the entire section was affected by precipitation. The tallest echoes are observed in southern France at 12 UTC, at the southern edge of the Massif Central Mountains $(y=200 \mathrm{~km})$ where deep convection, associated with the southerly feed of moisture originating from the Mediterranean Sea impinging on the slopes, is evident. The most intense cell extends up to $12 \mathrm{~km}$ (the top of the analysis domain) and exhibits reflectivity values of up to $55 \mathrm{dBZ}$. Weaker convective activity associated with frontal precipitation could be observed farther north between 350 and $500 \mathrm{~km}$. Convection along this section decreased significantly in the following hours as the frontal system progressed eastward toward the Rhone valley (Fig. 10b). A different precipitation regime can also be noticed at both times over Northern France $(y>500 \mathrm{~km})$, where widespread moderate stratiform precipitation could be observed in connection with the passage of the less intense rainband. 
As previously, a comparison with operational analyses was also performed to evaluate the consistency of the multiple-Doppler winds. This comparison is shown in Fig. 11 at 12 UTC for a height of $1.5 \mathrm{~km}$ AMSL. As for the Klaus case, one can note a good agreement between radar-derived and analyzed winds over the whole domain of analysis. The change in wind direction that indicates the location of the surface cold front is, for instance, almost identical in both datasets (inserts) although a slight difference can be noticed in the southern part of the domain (insert 2).

On 21 October 2009, a watch was ongoing for heavy precipitation and flash flood in the Cevennes area. Forecasters on duty were essentially focused on radar quantitative precipitation estimates and model quantitative precipitation forecasts in order to assess the hydrological risks. Three-dimensional wind and reflectivity observations would have also been quite useful to evaluate the quality of the weather forecast and to anticipate the future behavior of the storm. Indeed, a number of studies have shown that the distribution and intensity of precipitation over regions of complex terrain could be anticipated based on knowledge of the direction and strength of the wind impinging on the mountain chain (e.g., Ricard et al. 2012, Panziera and Germann 2010). Because the density of the radar network in the Rhone valley is greater than in any other part of the country (Fig. 1), it is, in this area, possible to produce higher resolution wind fields as well as to reconstruct the 3D airflow close to the ground. Examples of such capabilities are shown in Fig. 12, which presents high resolution $\left(1 \mathrm{~km}^{2}\right)$ multiple Doppler winds at 12 UTC and 15 UTC, 21 October 2009, within a domain of $200 \times 200 \mathrm{~km}^{2}$ shown in Fig. 9c. According to this time series that begins slightly before the arrival of the frontal system in the Rhone valley, the low-level flow impinging on the barrier was initially very strong (values up to $45 \mathrm{~ms}^{-1}$ ) and from the SE (Fig. 12a). This is consistent with the formation of heavy precipitation over the slopes and slightly off the Massif Central (Fig. 9). The strength of the low-level flow then weakened rapidly and progressively turned to S-to-SW'ly over the entire domain of analysis (Fig. 12b) following the eastward propagation of the cold front. Although local precipitation enhancement could be seen here and there, the low-level radar data suggest that the propagation of the cold front acted to sweep the convection away from the Rhone valley by suppressing the moisture feed originating from the Mediterranean Sea. Vertical cross-sections of reflectivity and retrieved vertical winds through areas of most intense precipitation (fig. 12c-d) also show good consistency between the location/intensity of updrafts and the 
position of the most active convective cells. Note, however, that the ability to retrieve realistic vertical winds is generally restricted to areas with good dual-Doppler coverage at low levels such as in Southern France or in the greater Paris area (Fig. 2a). Using numerically simulated radar observations over a 400x400 km² domain centered on Paris city, Bousquet et al. (2008a) have shown that the mean (resp. rms) error on retrieved vertical velocity was less than $0.6 \mathrm{~m} . \mathrm{s}^{-1}\left(\right.$ resp. $1 \mathrm{~ms}^{-1}$ ) throughout the troposphere.In most part of the country, the earth's curvature, beam blockage and large spacings between radars, actually prevent radar data from being available close to the surface (Fig. 2c), which can negatively impact on the quality of the retrieved vertical winds.

Overall, these high resolution wind fields nicely complement lower resolution multiple-Doppler analyses through providing a more detailed overview of the structure and evolution of precipitation and associated airflow at low-levels. These results also prefigure the new possibilities that will soon arise from the overall densification of the French operational radar network resulting from the ongoing deployment of numerous gap filling dual-polarimetric Doppler radars throughout continental France (Westrelin et al. 2011).

\section{Summary and future work}

The ability to collect Doppler measurements up to long range resulting from the deployment of a triple-PRT Doppler scheme within the French radar network ARAMIS allows to mitigate the Doppler dilemma ensuing from the inverse relationship between the unambiguous range and the unambiguous velocity (Doviak and Zrnic 1993) and to achieve extensive multiple-Doppler coverage while collecting high quality radial velocities. This achievement, which brings new perspectives in terms of exploitation of operational Doppler measurements, has brought the French weather service to develop a new mosaic of wind and reflectivity covering mainland France. To produce this composite analysis, reflectivity and radial velocity observations collected by the 24 ARAMIS radars that compose the French radar network are concentrated at the national weather center in Toulouse and synthesized every 15 minutes. An evaluation of multiple-Doppler wind fields synthesized in this framework was carried out from data collected during two weather situations characterized by fundamentally different airflow and precipitation regimes: the extratropical cyclone Klaus 
that struck France with hurricane strength winds on 24 January 2009, and a heavy orographic precipitation event that occurred over the Massif Central Mountains in 2009.

Wind and reflectivity fields produced routinely in this framework are archived since 2011 and are already fully available to researchers. In the future, these 3-D fields will be used to develop more efficient nowcasting algorithms, to investigate the dynamics and microphysics (using additional capabilities of polarimetric radar systems) of particular events, and to build a weather database for statistical analyses of continental weather systems. Radar-derived wind information produced in this operational framework will also eventually be used as inputs to automated tools for air traffic management purposes, as well as to evaluate (and correct) numerical model forecast through identifying possible temporal or spatial phase shift in model outputs. Such capabilities will be tested using model data produced in the frame of the HyMeX field phase during which a special version of this new radar product was used to guide research aircrafts over the Cevennes and Rhone valley areas. The HyMeX field phase will also provide the opportunity to thoroughly evaluate these wind fields through comparisons against independent in-situ measurements (aircraft data, radiosoundings) and mobile research radar data.

Although results presented in this paper are promising, a number of enhancements are still needed for this product to become fully operational. This includes, for instance, an improvement of reflectivity measurements through correcting for partial beam filling and rain attenuation. The latter information is already available from dual-polarimetric radar systems (Figueras et al. 2012) and will shortly be accounted for in the fabrication of the reflectivity mosaic. Also, even though airflows retrieved during the events presented in this paper compared well with operational model analyses, there is still a long way to go in order to thoroughly evaluate the composite wind fields. In this respect a 1-year monitoring procedure will soon be implemented to compare radar winds against operational model analyses and forecasts. As of today we expect the 3D reflectivity mosaic to become operational in mid-2013. This operational reflectivity product will be eventually complemented with 3D wind data about 1 year later. 


\section{References}

Armijo, L., 1969: A Theory for the Determination of Wind and Precipitation Velocities with Doppler Radars. J. Atmos. Sci., 26, 570-573.

Augros, C., and P. Tabary, 2009: Improvements of the French operational triple PRT Doppler scheme. Preprints, 34th Conference on Radar Meteorology, Williamsburg, USA.

Augros, C., P. Tabary, A. Anquez, J-M Moisselin, P. Brovelli and O. Bousquet, 2013: Development of a nation-wide low-level wind-shear mosaic in France. Accepted in Wea. Forecast. pending minor revisions.

Beck, J. and O. Bousquet, 2012: Using gap filling radars to achieve operational multiple-Doppler wind synthesis retrieval in mountainous area. Accepted in J. Appl. Meteorol. Clim.

Bousquet, O., and M. Chong, 1998: A multiple Doppler and continuity adjustment technique (MUSCAT) to recover wind components from Doppler radar measurements. J. Atmos. Oceanic Technol., 15, 343-359.

Bousquet, O., P. Tabary, and J. Parent du Châtelet, 2007: On the value of operationally synthesized multipleDoppler wind fields, Geophys. Res. Lett., 34, L22813, doi:10.1029/2007GL030464.

Bousquet, O., P. Tabary, and J. Parent du Châtelet, 2008a: Operational multiple-Doppler wind retrieval inferred from long range radar velocity measurements, J. Appl. Meteorol. Clim., 47, 2929-2945.

Bousquet, O., T. Montmerle, and P. Tabary, 2008b: Using operationally synthesized multiple-Doppler winds for high resolution NWP model horizontal wind verification. Geophys. Res. Lett., 35, L10803, doi:10.1029/2008GL033975.

Bousquet, O., 2009: Dynamical and microphysical properties of high impact orographic mesoscale convective systems from high resolution operational multiple-Doppler and polarimetric radar data. Preprints, 34th Conference on Radar Meteorology, Williamsburg, USA

Browning K., A., and R. Wexler, 1968: The determination of kinematic properties of a wind field using Doppler radar, J. Appl. Meteorol., 7, 105-113. 
Browning, K.A., 1999: Mesoscale aspects of extratropical cyclones: An observational perspective. in Life Cycles of Extratropical Cyclones, American Meteorological Society, Boston, 265-283.

Browning, K.A., 2004: The sting at the end of the tail: Damaging winds associated with extratropical cyclones. Quart. J. Roy. Meteor. Soc., 130, 375-399.

Davies-Jones, Robert P., 1979: Dual-Doppler Radar Coverage Area as a Function of Measurement Accuracy and Spatial Resolution. J. Appl. Meteor., 18, 1229-1233.

Delrieu, G., and co-authors, 2005: The Catastrophic Flash-Flood Event of 8-9 September 2002 in the Gard Region, France: A First Case Study for the Cévennes-Vivarais Mediterranean Hydrometeorological Observatory. Journal of Hydrometeorology, 6, 34-52.

Dolan, B. A., and S. A. Rutledge, 2007: An integrated display and analysis methodology for multivariable radar data. J. Appl. Meteorol. Clim., 46, 1196-1213.

Doviak, R. J., and D. S. Zrnic, 1993: Doppler Radar and Weather Observations. 2nd ed. Academic Press, $562 \mathrm{pp}$.

Figueras i Ventura, J, A.-A. Boumahmoud, B. Fradon, P. Dupuy and P. Tabary, 2012. Long-term monitoring of French polarimetric radar data quality and evaluation of several polarimetric quantitative precipitation estimators in ideal conditions for operational implementation at C-band., Quart. J. Roy. Meteor. Soc., 130, 375-399., in press.

Frasier, S.J., F. Kabèche, J. Figueras i Ventura, H. Al-Sakka, P. Tabary, J. Beck and O. Bousquet, 2012: Insitu Estimation of Wet-Radome Attenuation at X-band, Journal of Atmospheric and Oceanic Technology, accepted pending minor revision.

Gao, Feng, 2009: Fast k-Nearest-Neighbors Calculation for Interpolation of radar Reflectivity Field*. $J$. Atmos. Oceanic Technol., 26, 1410-1414.

Gourley, Jonathan J., Pierre Tabary, Jacques Parent du Chatelet, 2007: A Fuzzy Logic Algorithm for the Separation of Precipitating from Nonprecipitating Echoes Using Polarimetric Radar Observations. $J$. Atmos. Oceanic Technol., 24, 1439-1451. 
He, G., G. Li, X. Zou,, and P. S. Ray, 2012: Applications of a Velocity Dealiasing Scheme to Data from the China New Generation Weather Radar System (CINRAD). Wea. Forecasting, 27, 218-230.

McLaughlin, D., and co-authors, 2009. Short-wavelength technology and the potential for distributed networks of small radar systems. Bulletin of the American Meteorological Society 90: 1797-1817.

Montmerle, T., and C. Faccani, 2009: Mesoscale assimilation of radial velocities from Doppler radar in a pre-operational framework. Mon. Wea. Rev.,137, 1939-1953.

Park, S-G., Dong-Kyou Lee, 2009: Retrieval of High-Resolution Wind Fields over the Southern Korean Peninsula Using the Doppler Weather Radar Network. Wea. Forecasting, 24, 87-103.

Radnóti, G., R. Ajjaji, R. Bubnovà, M. Caian, E. Cordoneanu, K. von der Emde, J.-D. Gril, J. Hoffman, A. Horànyi, S. Issara, V. Ivanovici, M. Janousek, A. Joly, P. Le Moigne, S. Malardel, 1995 : The spectral limited area model Arpege/Aladin. PWPR Report Series n 7, WMO T.D. N. 799, 111-118.

Ray, P. S. and K. K. Wagner (1976), Multiple Doppler radar observations of storms, Geophys. Res. Lett., 3(3), 189-191, doi:10.1029/GL003i003p00189.

Ray, P. S., C. L. Ziegler, W. Bumgarner and R. J. Serafin, 1980: Single- and multiple-Doppler radar observations of tornadic storms. Mon. Wea. Rev., 108, 1607-1625.

Rude, D. J., E. J. Bass, and B. Philips, 2012: Quantifying the impact of adding gap filling radar data on forecaster wind assessments, warnings, and confidence. Quart. J. R Meterol. Soc., in press

Schultz et al. 1998: The Effect of Large-Scale Flow on Low-Level Frontal Structure and Evolution in Midlatitude Cyclones. Mon. Wea. Rev., 126, 1767-1791.

Shapiro, M. A., and D. Keyser, 1990: Fronts, jet streams and the tropopause. Extratropical Cyclones, The Erik Palmén Memorial Volume, C. W. Newton and E. O. Holopainen, Eds., Amer. Meteor. Soc., 167-191.

Sugier, J., J. Parent-du-Châtelet, P. Roquain, and A. Smith, 2002: Detection and removal of clutter and anaprop in radar data using a statistical scheme based on echo fluctuation. Proc. Second European Radar Conf., Delft, Netherlands, Copernicus GmbH, 17-24. 
Tabary, P., L. Perier, J. Gagneux, and J. Parent-du-Chatelet, 2005 : Test of a staggered PRT scheme for the French radar network.. J. Atmos. Oceanic Technol., 22, 352-364.

Tabary, P., F. Guibert, L. Perier, and J. Parent-du-chatelet, 2006: An operational triple-PRT scheme for the French radar network. J. Atmos. Oceanic Technol., 23, 1645-1656.

Tabary, P., A.A. Boumahmoud, H. Andrieu, R. J. Thompson, A. J. Illingworth, E. Le Bouar and J. Testud, 2011: Evaluation of two "integrated” polarimetric Quantitative Precipitation Estimation (QPE) algorithms at C-band, Journal of Hydrology, 405., 248,260.

Torres S. M., Y. F. Dubel, and D. S. Zrnić, 2004: Design, implementation, and demonstration of a staggered PRT algorithm for the WSR-88D., J. Atmos. Oceanic Technol., 21, 1389-1399.

Tuttle, J. D., and G. B. Foote, 1990: Determination of boundary layer airflow from a single Doppler radar. J. Atmos. Oceanic Technol., 7, 218-232.

Wernli, H., Dirren, S., Liniger, M. A. and Zillig, M., 2002, Dynamical aspects of the life cycle of the winter storm 'Lothar' (24-26 December 1999). Quart. J. Roy. Meteor. Soc, 128, 405-429

Zhang, J., K. Howard, and J. J. Gourley, 2005: Constructing Three-Dimensional Multiple-Radar Reflectivity Mosaics: Examples of Convective Storms and Stratiform Rain Echoes. J. Atmos. Oceanic Technol., 22, $30-42$.

Zhang, J., and S. Wang, 2006: An automated 2D multipass Doppler radar velocity dealiasing scheme. $J$. Atmos. Oceanic Technol., 23, 1239-1248.

Zrnic, D. S., and P. Mahapatra, 1985: Two methods of ambiguity resolution in pulsed Doppler weather radars., IEEE Trans. Aerosp. Electron. Syst., 21, 470-48. 


\section{Captions}

Table 1: Elevation angles $\left({ }^{\circ}\right)$ used in the scanning strategy of the French radars as of January 2012. Boldface values indicate beam elevations that are used for multiple-Doppler wind retrieval.

Symbol * denotes the 3 radars not yet equipped with Doppler capabilities in 2009. ** The Aléria radar (Corsica) is not used in the paper.

Figure 1: Map of the French operational radar network ARAMIS as of December 2012. The $100 \mathrm{~km}(50 \mathrm{~km}$ for X-band) ranges of measurement associated with each radar are shown by circles. Green, purple and yellow colors correspond to C-, S-, and X-band radars, respectively.

Figure 2: Maximum theoretical radar coverage ensuing from radar scanning strategies demonstrated in Table 1, within the 1000x1000 $\mathrm{km}^{2}$ Cartesian domain used to construct the radar composite. The coverage is obtained by taking into account beam blockage by terrain and by considering a fixed horizontal radius of influence of $3 \mathrm{~km}$ and a variable vertical radius of influence equals to $1^{\circ}$ for the Cressman weighting functions (see text for details). (a) Horizontal map showing number of radars with overlapping coverage at (a) $500 \mathrm{~m}$ and (b) $1000 \mathrm{~m}$ AMSL. (c) Radar coverage as a function of height between 0.5 and $12 \mathrm{~km}$. The plain, dashed and dotted lines indicate the fraction of land (\%) covered by at least one, two, and three radars, respectively. In (a-b) colors indicate regions of single- (light gray), dual- (medium gray), and multipleDoppler (dark gray) coverage. Black contours show terrain heights above $500 \mathrm{~m}$.

Figure 3: Meteosat Second Generation (MSG) infrared satellite imagery (10.8 $\mu \mathrm{m})$ over Western Europe, valid at (a) 00 UTC and (b) 6 UTC, 24 January 2009. 
Figure 4: Surface wind data on 24 January 2009. (a) Surface analysis over Western Europe valid at 0 UTC. (b) Recorded maximum surface wind speed during the passage of storm Klaus over France. The black dashed square in (a) shows the area where the wind retrieval is performed. The trajectory and central pressure of the cyclone are also indicated in (b).

Figure 5: Multiple-Doppler analysis of radar data at $2 \mathrm{~km}$ AMSL within the $1000 \times 1000 \mathrm{~km}^{2}$ domain shown in Fig. 2. Wind direction (vectors) superimposed on radar reflectivity (colour shading, dBZ), and wind speed (colour shading, lower panel) valid at (a-b) 03UTC and (c-d) 06UTC, 24 January 2009. One in every sixth vector is plotted. Frontal boundaries deduced from surface analyses are shown in (a) and (c). In (c) black arrows indicate the positions of rain bands possibly associated with slantwise circulations. Black box in (d) indicates the area where the comparison against surface wind data is performed.

Figure 6: As in Fig. 5 but for 9 UTC (a-b) and 12 UTC (c-d).

Figure 7: Comparison between ALADIN operational winds (blue) and multiple-Doppler winds (red) at 1500 AMSL and 6 UTC, 24 January 2009. Black squares show areas highlighted in inserts 1 and 2.

Figure 8: Overview of meteorological conditions on 21 October 2009. (a) Operational analysis of geopotential height at $500 \mathrm{hPa}$ valid at 12 UTC. (b) Operational surface analysis valid at 12 UTC. (c) 24-h accumulated precipitation $(\mathrm{mm})$ over France starting at 00 UTC. In (c) the red cross indicates the location of Villefort.

Figure 9: Multiple-Doppler analysis of radar data at $2 \mathrm{~km}$ AMSL within the 1000 x $1000 \mathrm{~km}^{2}$ domain shown in Fig. 2 on 21 October 2009. Wind vectors superimposed on radar reflectivity (colour shading, dBZ) valid at 
(a) 0UTC, (b) 6UTC, (c) 12UTC and (d) 18UTC. Red solid lines show the location of cross-sections shown in Fig. 10. The white box in (c) indicates the display domain for Fig. 12. One in every sixth vector is plotted. Black shading shows terrain above $500 \mathrm{~m}$.

Figure 10: Vertical cross-sections of radar reflectivity (dBZ) along red lines shown in Fig. 9 based upon data collected at (a) 12 UTC and (b) 18 UTC, 21 October 2009. Outline of underlying terrain is indicated by a continuous medium-grey line.

Figure 11: As in Fig. 7, but for 21 October 2009 at 12 UTC. Black plain (resp. dashed) line in inserts 1 and 2 shows the location of the surface cold front deduced from model (resp. radar) wind data.

Figure 12: High horizontal resolution $\left(1 \mathrm{~km}^{2}\right)$ multiple-Doppler analysis of radar data on 21 October 2009, within the domain of $200 \mathrm{~km}$ x $200 \mathrm{~km}$ shown in Fig. 9c. Upper panels show radar reflectivity (dBZ, colour shaded) and wind vectors at 500m AMSL valid at (a) 12 UTC and (b) 15 UTC. One in every fifth vector is plotted. Lower panel show vertical cross-sections of reflectivity and vertical velocity at (c) 12 UTC and $x=45 \mathrm{~km}$ and (d) 15 UTC and $x=176 \mathrm{~km}$. In (a-b), black shading indicates Massif Central (left hand side) and Alps (right hand side) mountain chains. White lines show locations of vertical cross-sections shown in (c-d). In (c-d) black contours show areas of vertical velocity higher than $1 \mathrm{~ms}^{-1}$ (plain) and $3 \mathrm{~ms}^{-1}$ (bold). Dashed line shows area of negative vertical velocity lower than $-1 \mathrm{~ms}^{-1}$. Outline of underlying terrain is indicated by continuous medium-grey line. 
TABLE 1: Elevation angles $\left(^{\circ}\right)$ used in the scanning strategy of the French radars as of December 2012. Boldface values indicate beam elevations that are used for multiple-Doppler wind retrieval.

Symbol * denotes the 3 radars not yet equipped with Doppler capabilities in 2009. ** The Aléria radar (Corsica) is not used in the paper. Symbol DPOL indicates radars equipped with dual-polarimetric capabilities.

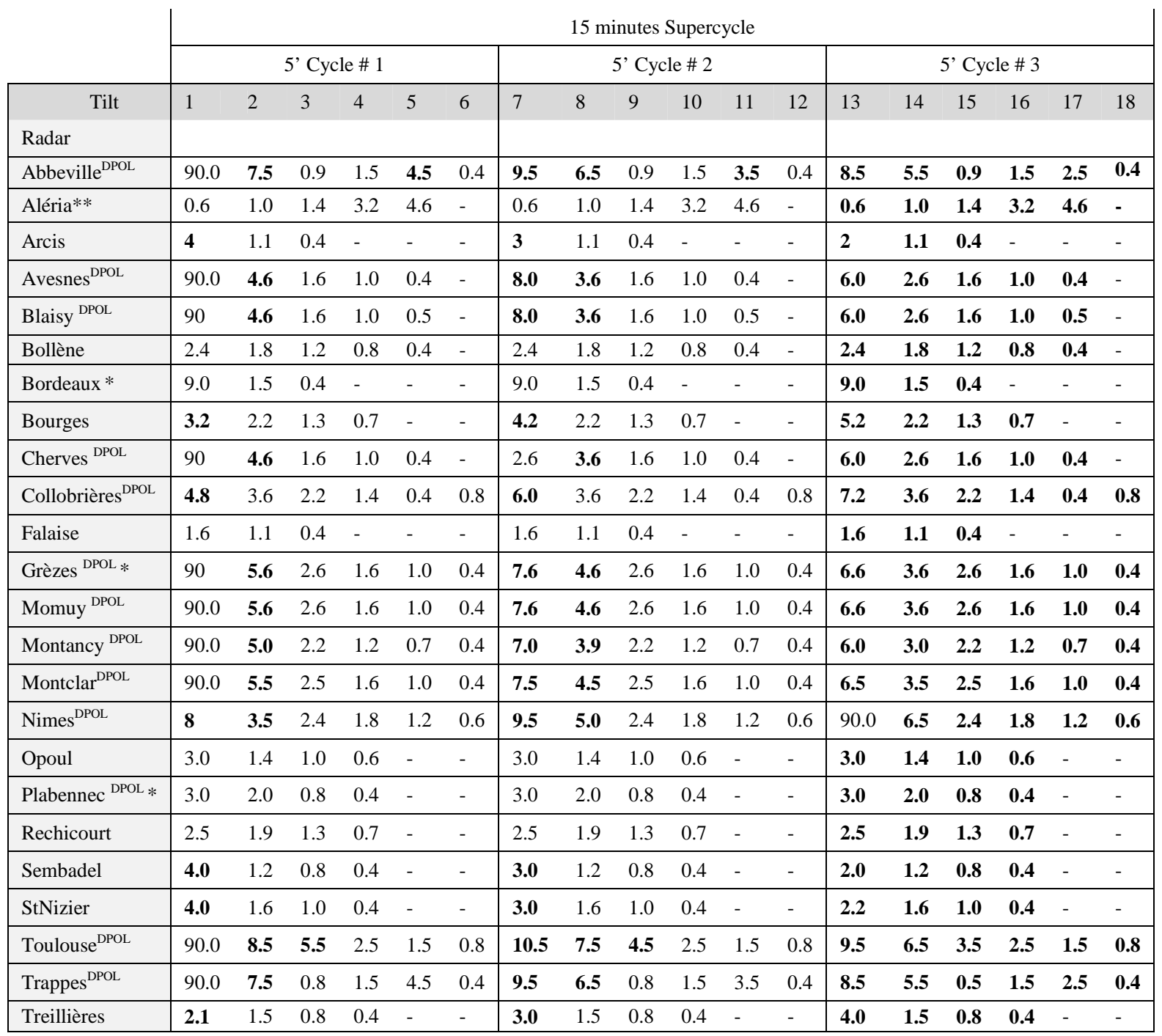




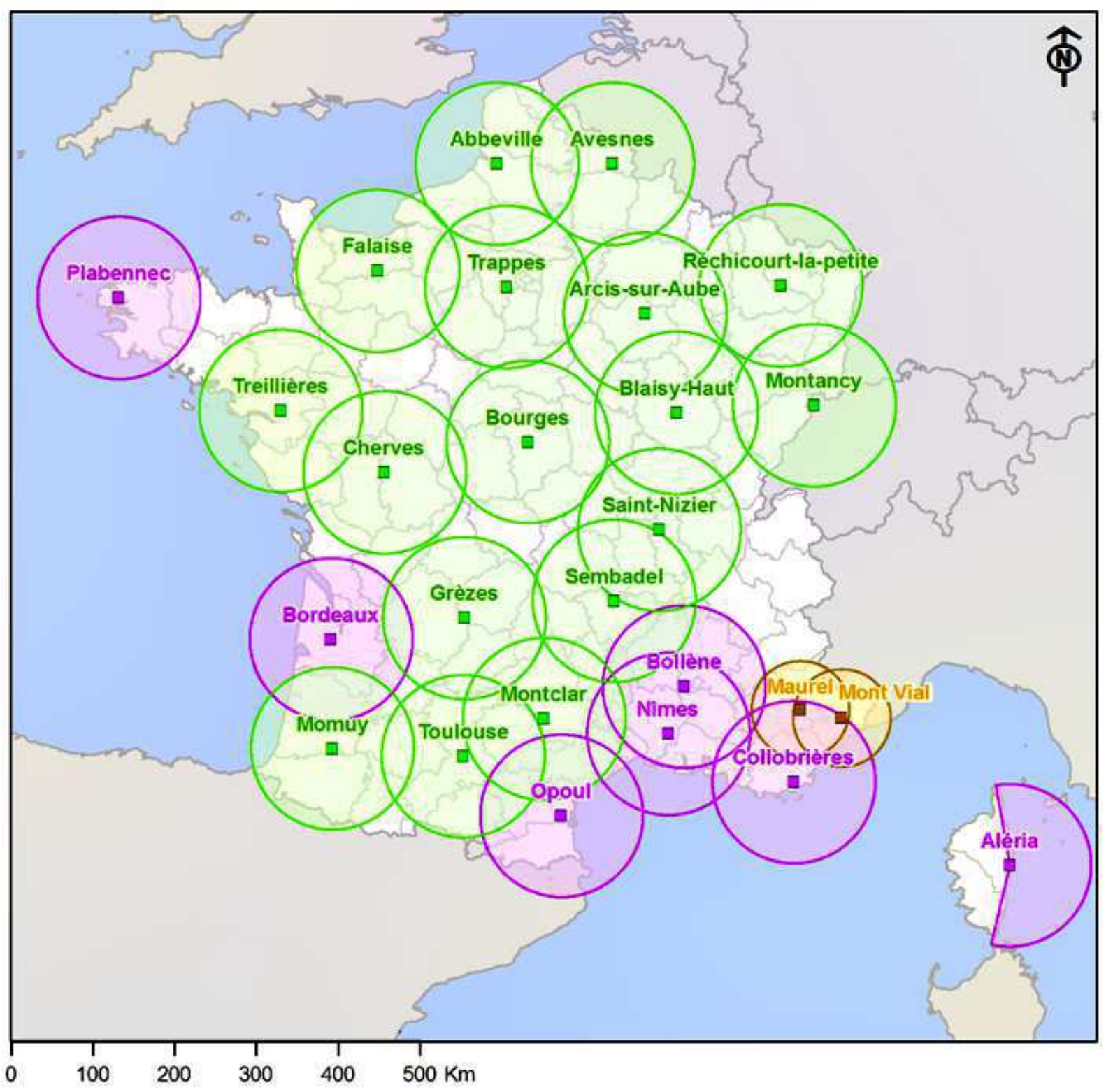

Figure 1: Map of the French operational radar network ARAMIS as of December 2012. The $100 \mathrm{~km}(50 \mathrm{~km}$ for X-band) ranges of measurement associated with each radar are shown by circles. Green, purple and yellow colors correspond to C-, S-, and X-band radars, respectively. 
(a)

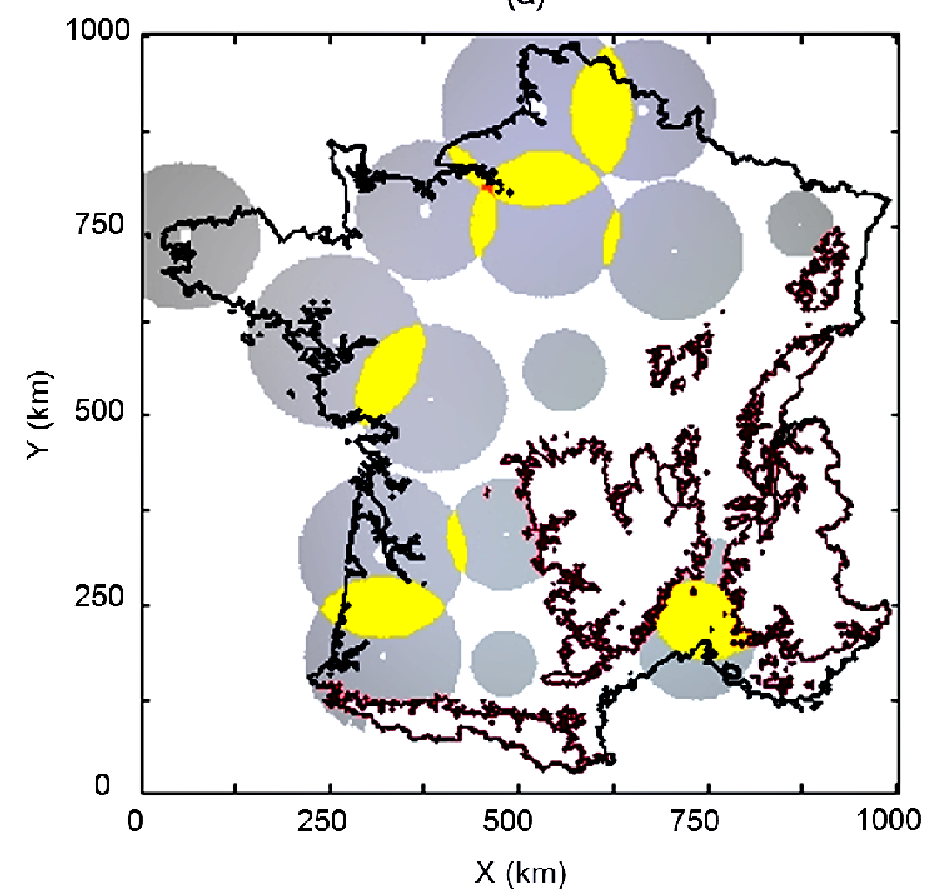

(b)

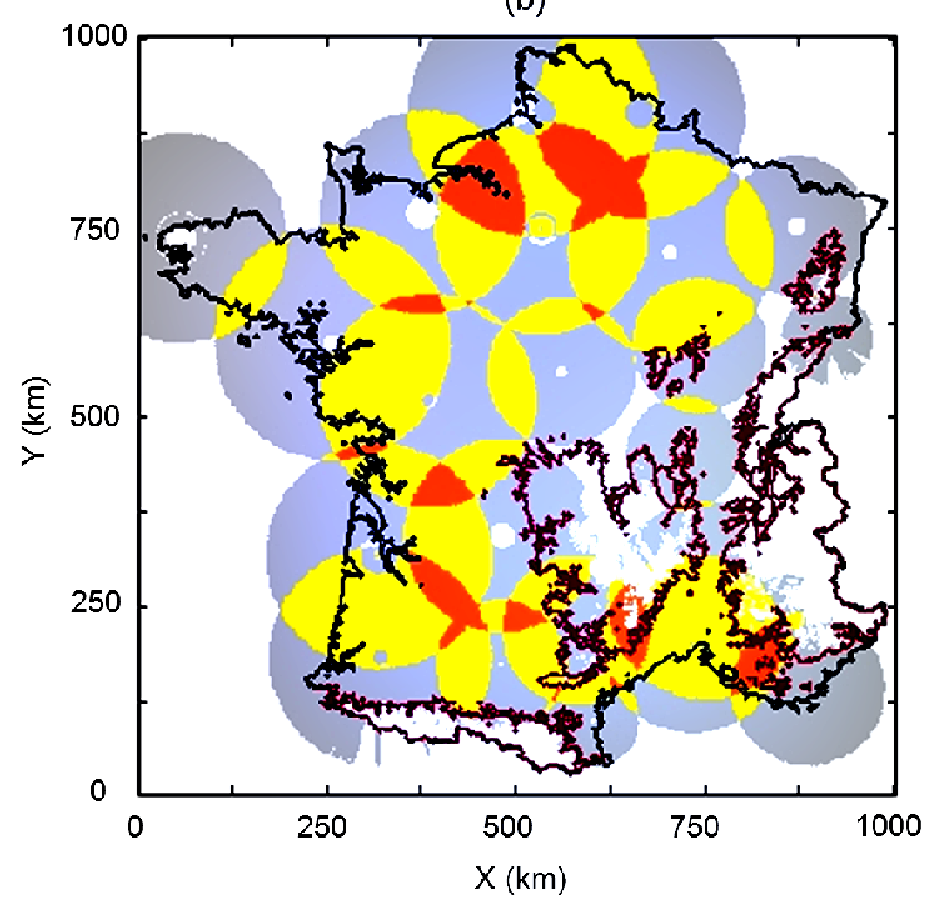

(c)

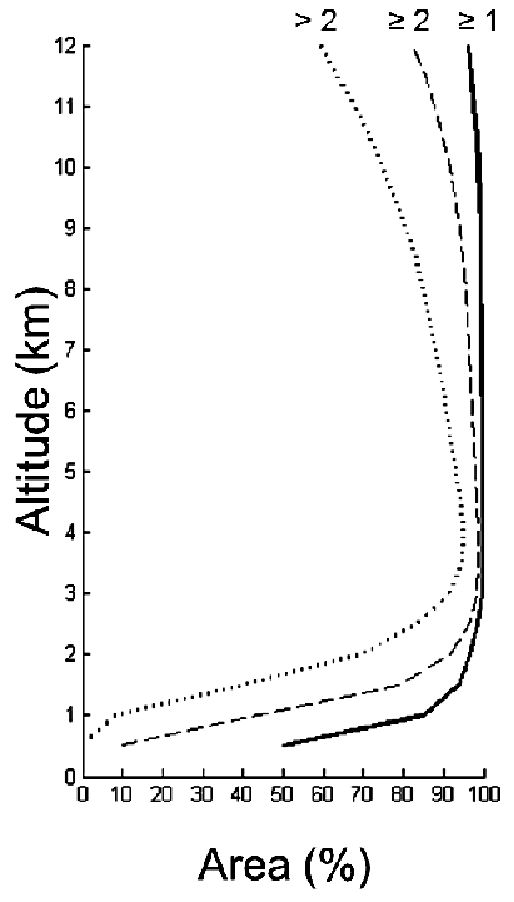

Figure 2: Maximum theoretical radar coverage ensuing from radar scanning strategies demonstrated in Table 1, within the $1000 \times 1000 \mathrm{~km}^{2}$ Cartesian domain used to construct the radar composite. The coverage is obtained by taking into account beam blockage by terrain and by considering a fixed horizontal radius of influence of $3 \mathrm{~km}$ and a variable vertical radius of influence equals to $1^{\circ}$ for the Cressman weighting functions (see text for details). (a) Horizontal map showing number of radars with overlapping coverage at (a) $500 \mathrm{~m}$ and (b) $1000 \mathrm{~m}$ AMSL. (c) Radar coverage as a function of height between 0.5 and $12 \mathrm{~km}$. The plain, dashed and dotted lines indicate the fraction of land (\%) covered by at least one, two, and three radars, respectively. In (a-b) colors indicate regions of single- (light gray), dual- (yellow), and multiple-Doppler (orange) coverage. Red contours show terrain heights above $500 \mathrm{~m}$. 


\section{(a) DOUTC}

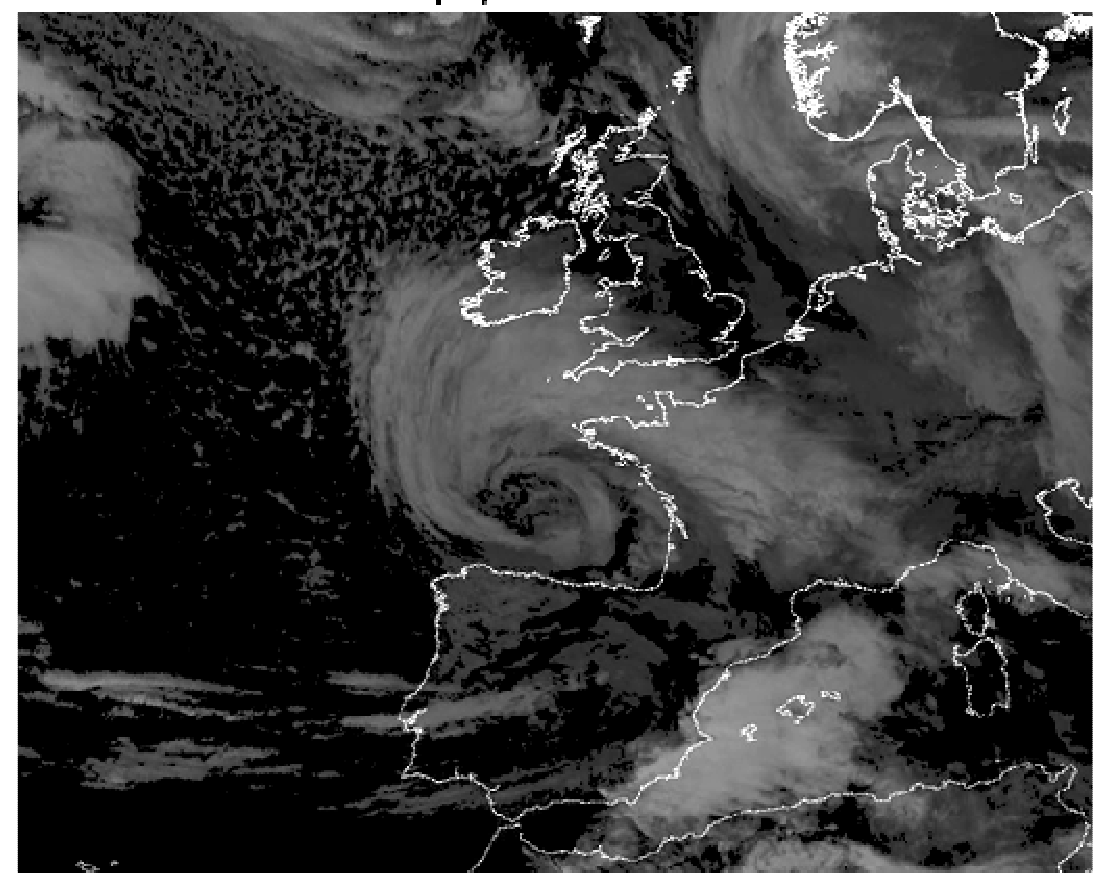

\section{(b) 06UTC}

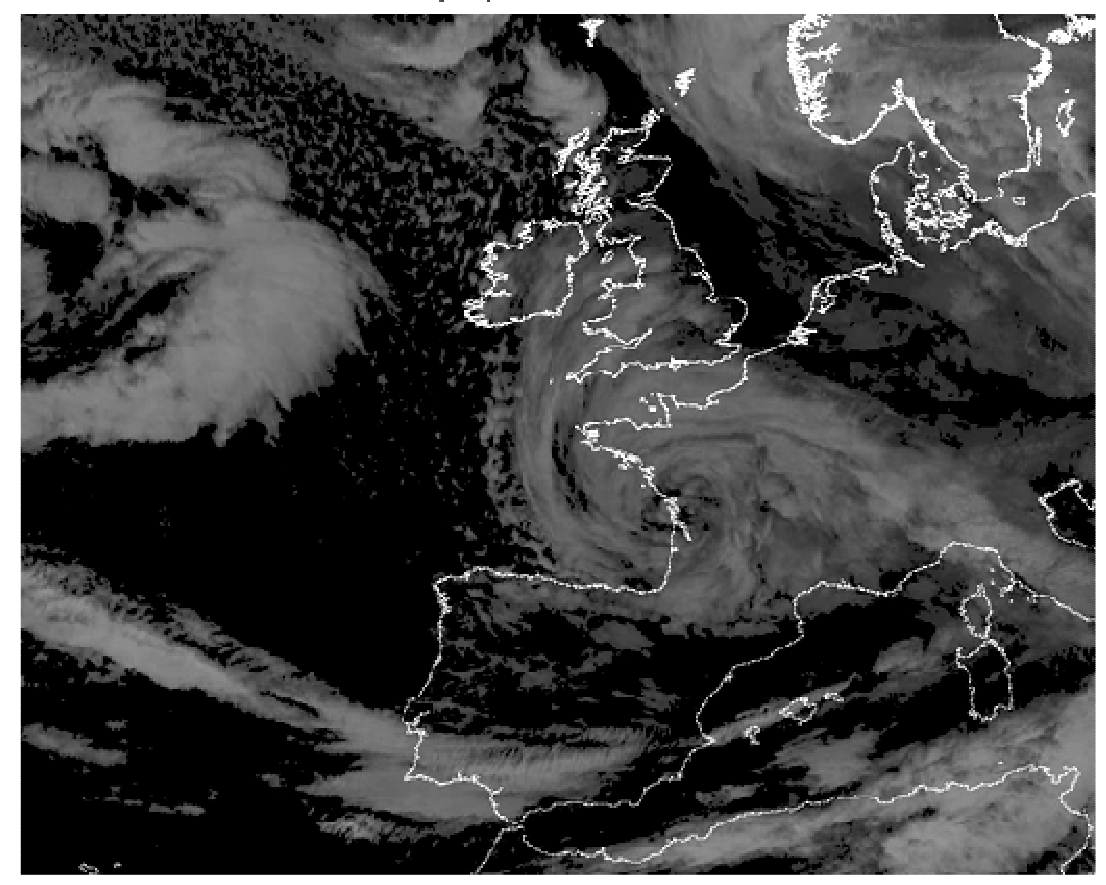

Figure 3: Meteosat Second Generation (MSG) infrared satellite imagery over Western Europe, valid at (a) 00 UTC and (b) 6 UTC, 24 January 2009. 
(a) Surface Analysis 00UTC

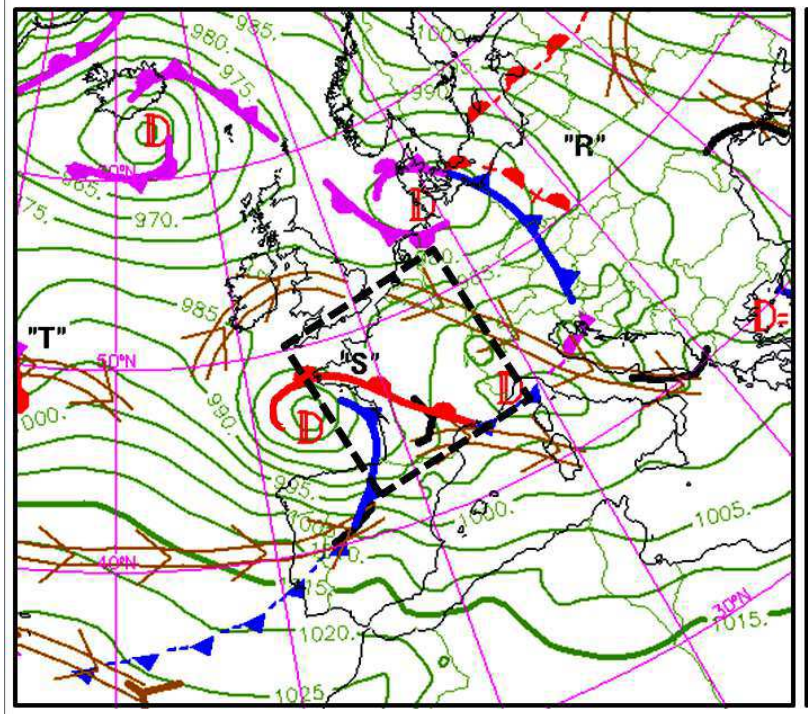

(b) Maximum wind speed

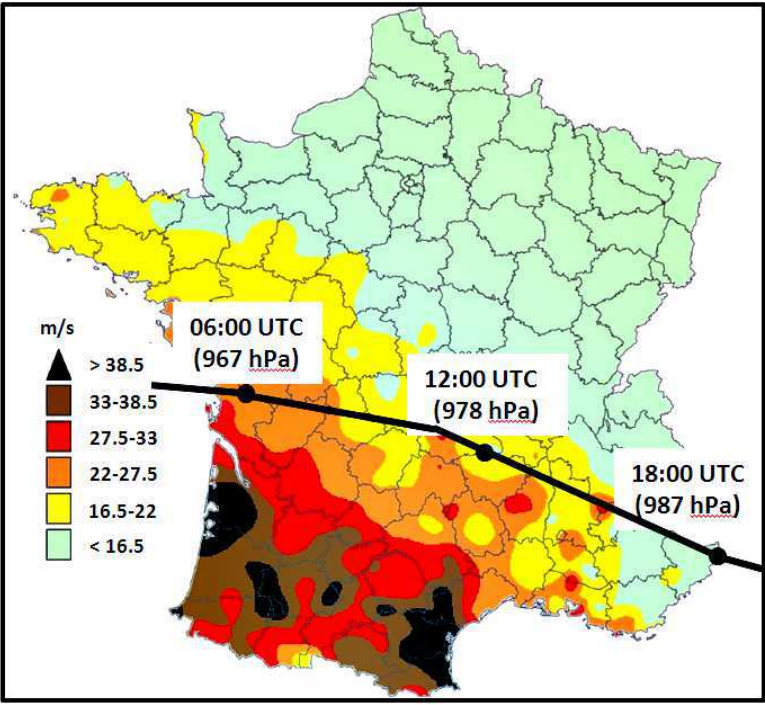

Figure 4: Surface data on 24 January 2009. (a) Surface analysis over Western Europe valid at 0 UTC. (b) Recorded maximum surface wind speed during the passage of storm Klaus over France. The black square in (a) shows the area where the wind retrieval is performed. The trajectory and central pressure of the cyclone are also indicated in (b). 

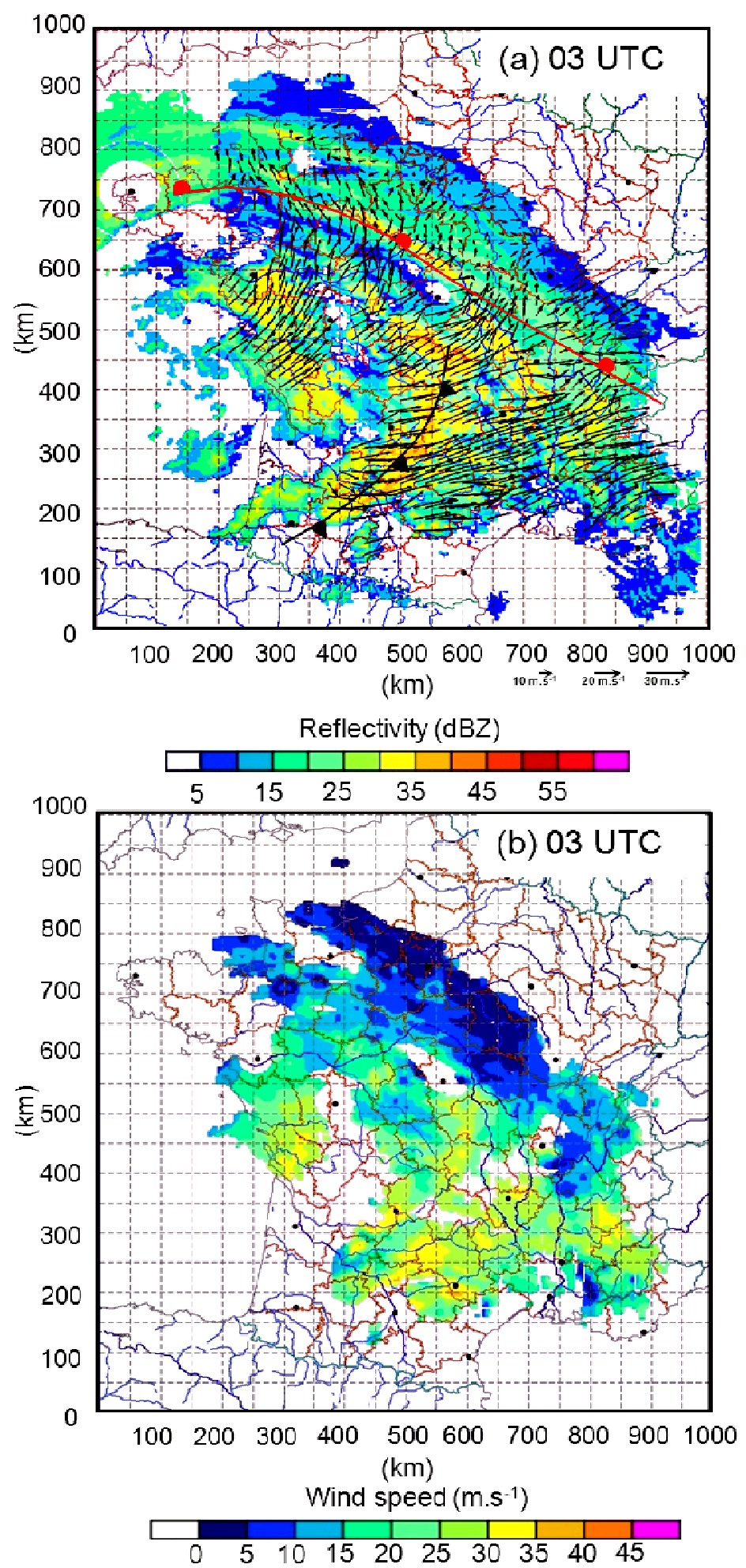

Figure 5: Multiple-Doppler analysis of radar data at $2 \mathrm{~km}$ AMSL within the $1000 \mathrm{x} 1000 \mathrm{~km}^{2}$ domain shown in Fig. 2. Wind direction (vectors) superimposed on radar reflectivity (colour shading, dBZ), and wind speed (colour shading, lower panel) valid at (a-b) 03UTC and (c-d) 06UTC, 24 January 2009. One in every sixth vector is plotted. Frontal boundaries deduced from surface analyses are shown in (a) and (c). In (c) black arrows indicate the positions of rain bands possibly associated with slantwise circulations. Black box in (d) indicates the area where the comparison against surface wind data is performed. 

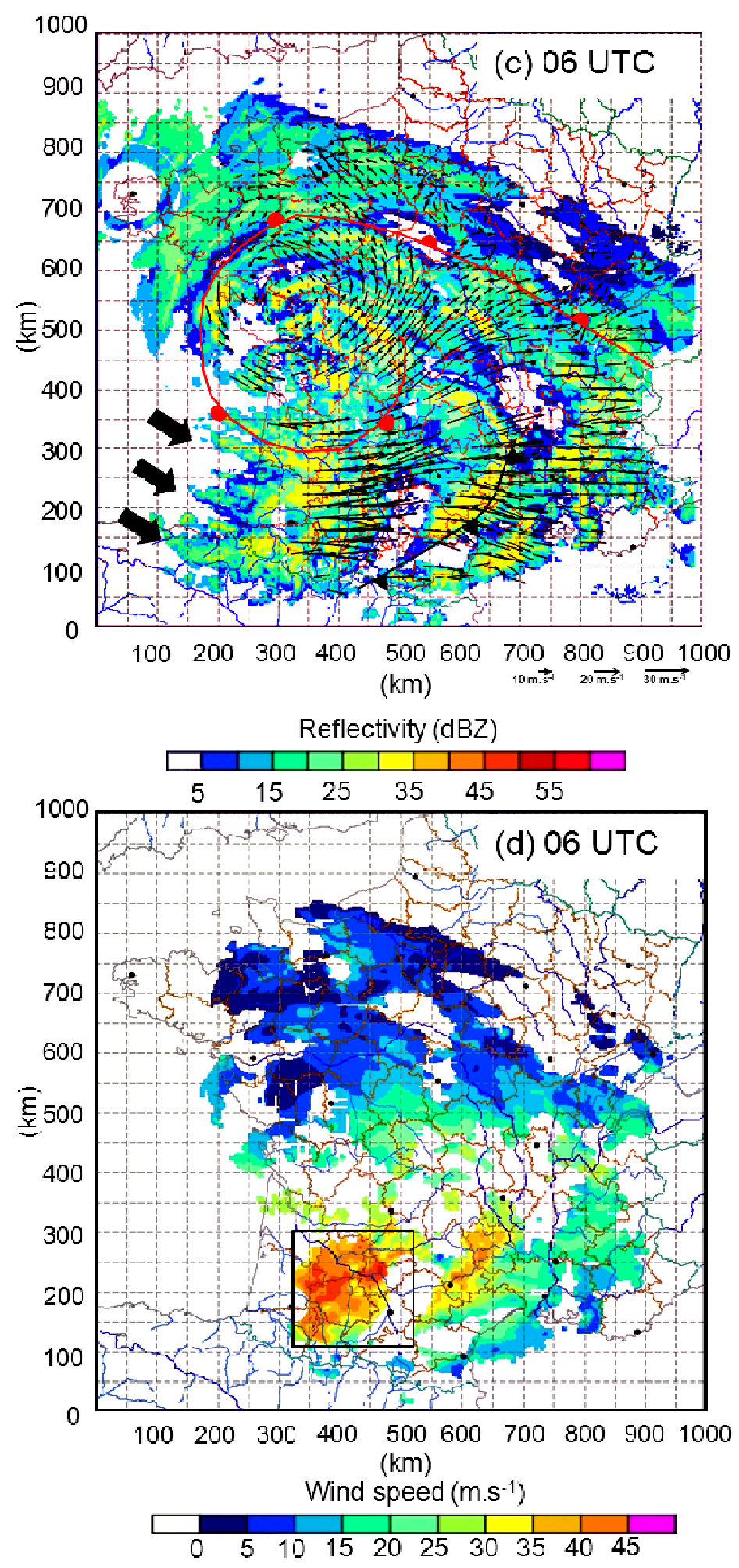

Figure 5: ctn 

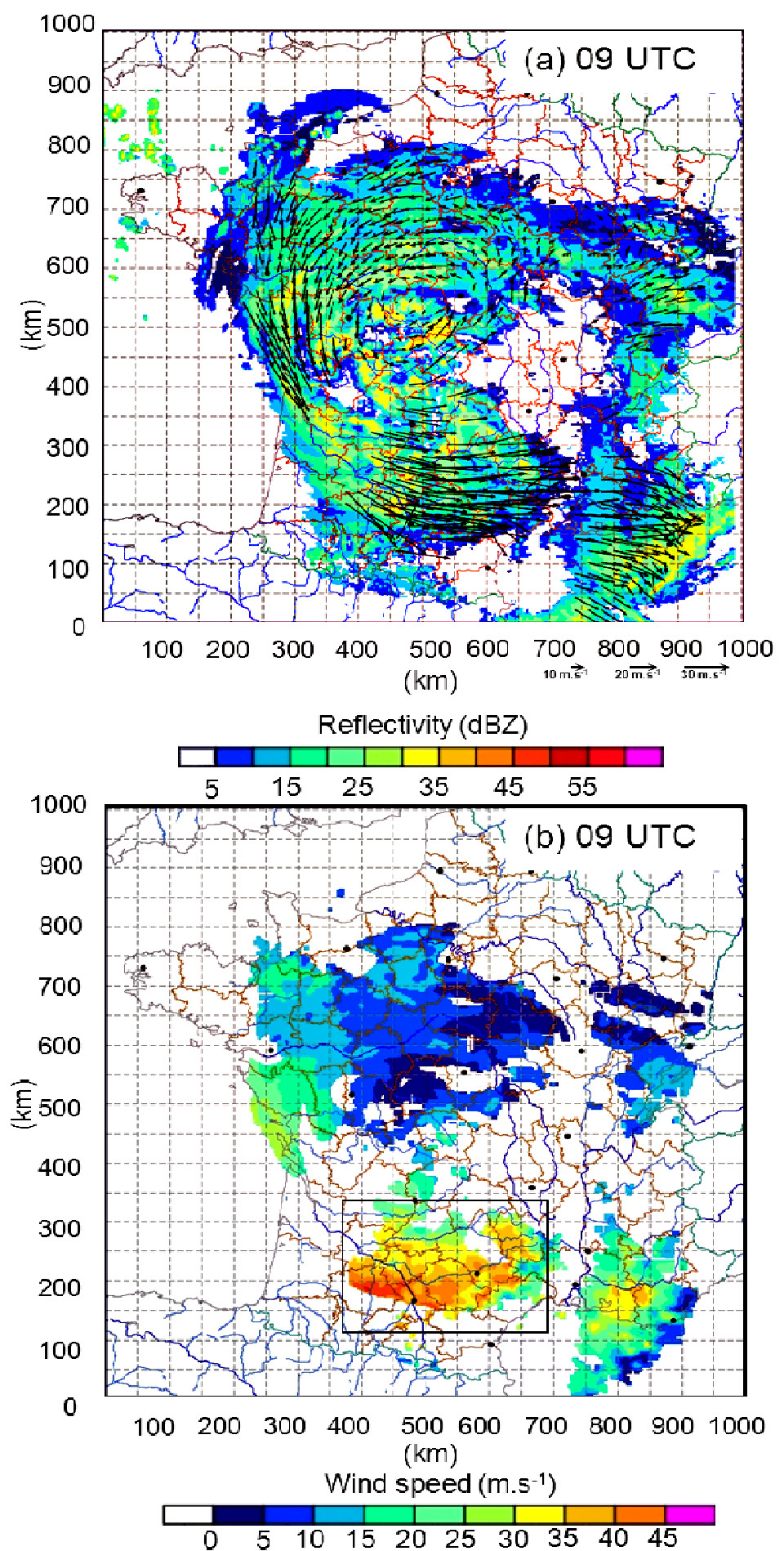

Figure 6: As in Fig. 5 but for 9 UTC (a-b) and 12 UTC (c-d). 


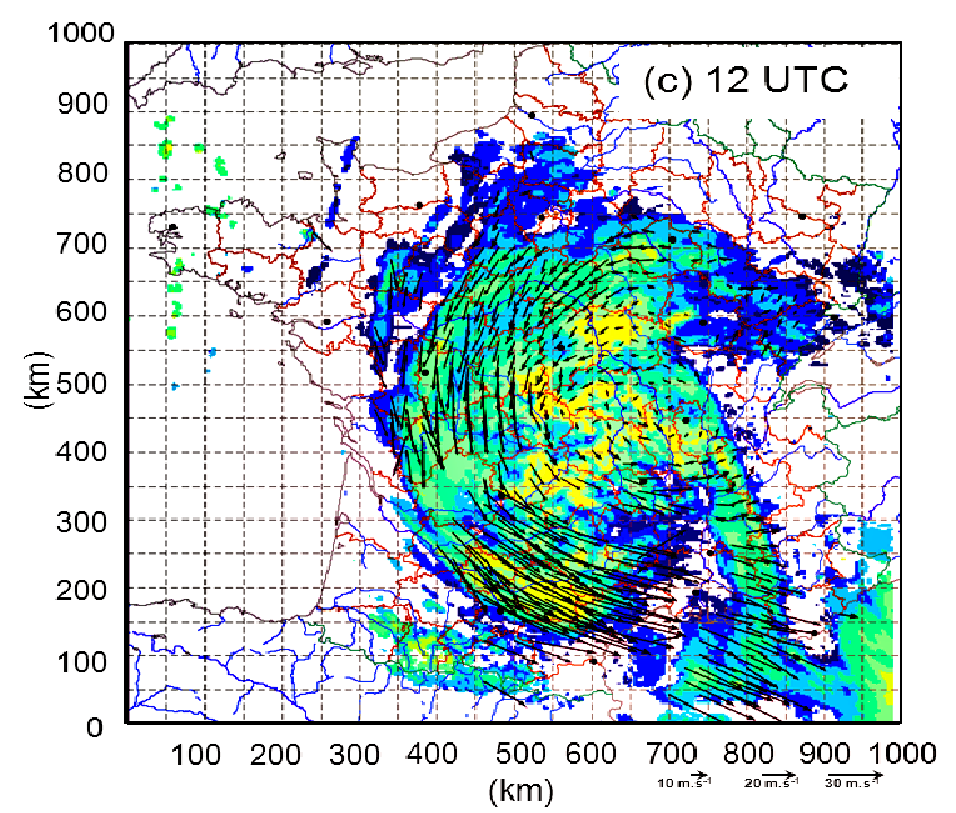

Reflectivity (dBZ)

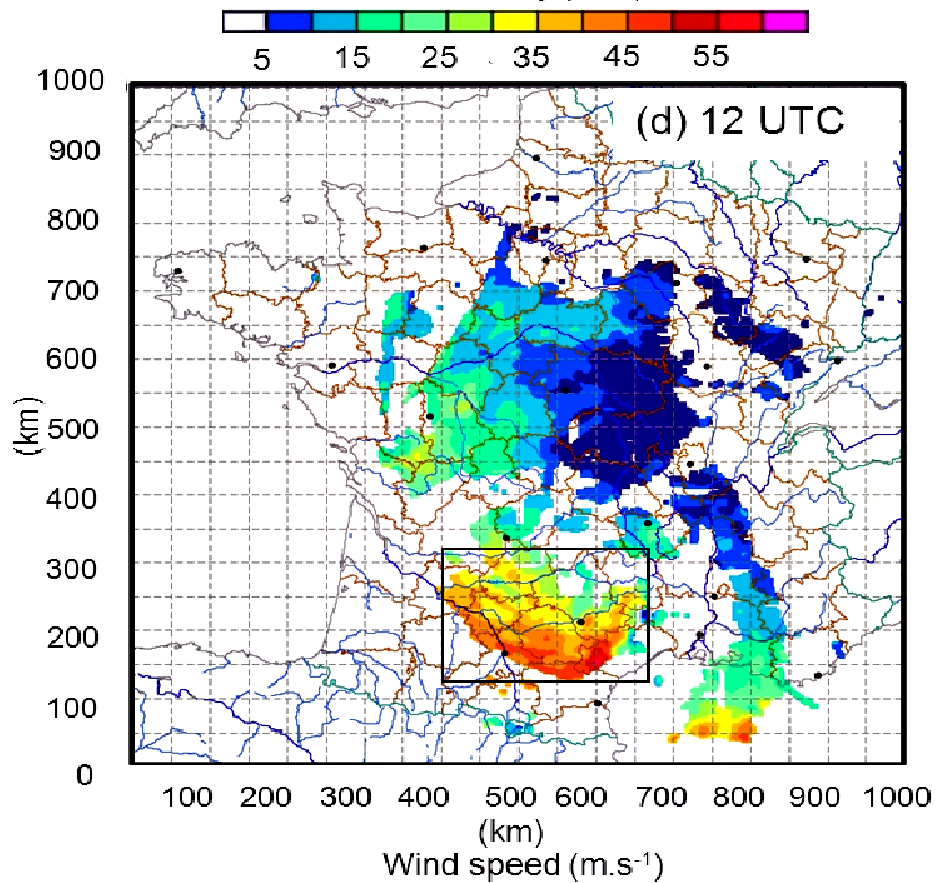

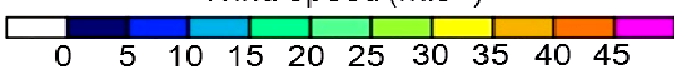

Figure 6 : ctnd 

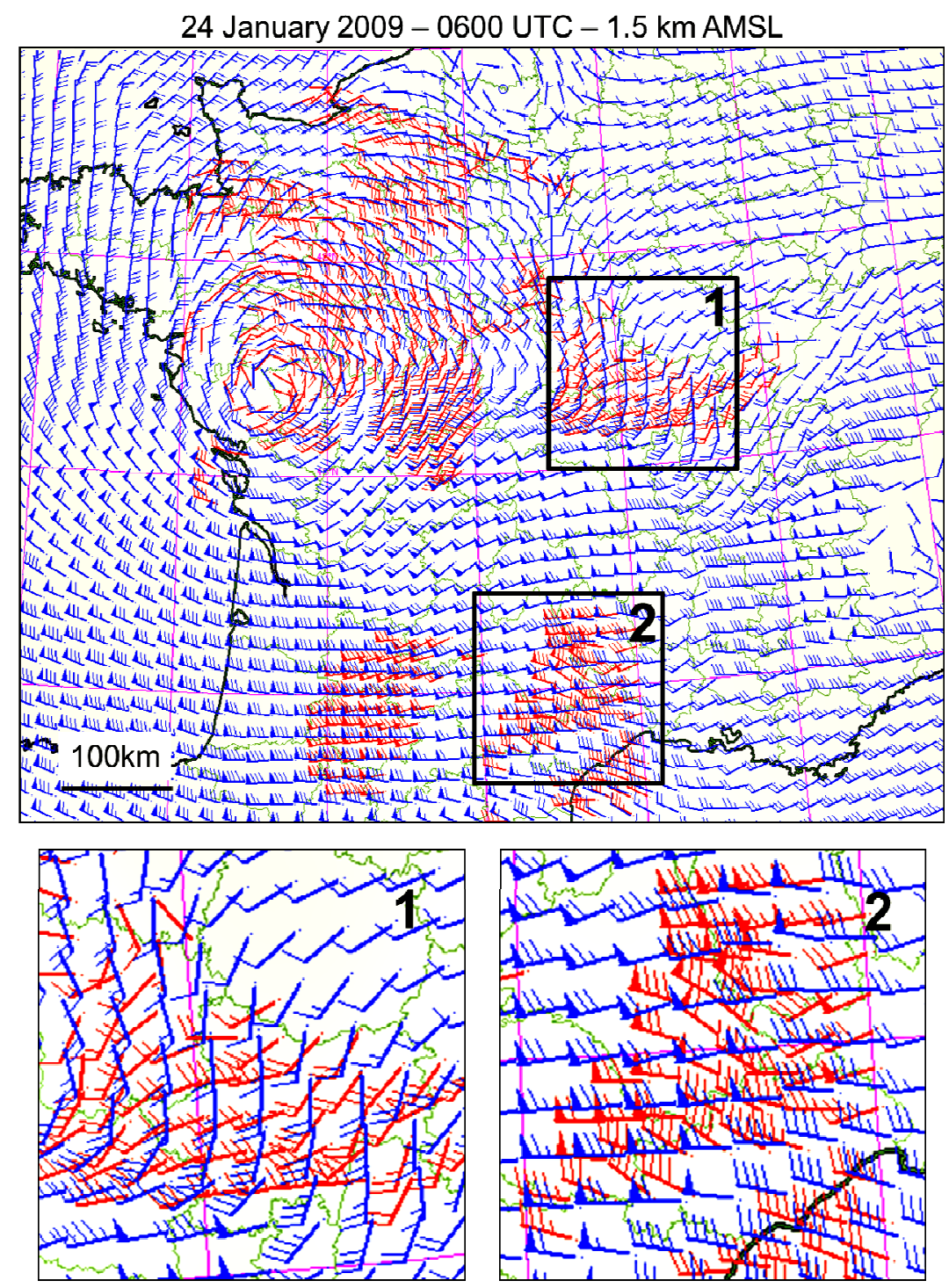

Figure 7: Comparison between ALADIN operational winds (blue) and multiple-Doppler winds (red) at 1500 AMSL and 6 UTC, 24 January 2009. Black squares show areas highlighted in inserts 1 and 2. 
(a) $20091021-12 \mathrm{UTC}-\mathrm{Z}(\mathrm{m})$ at $500 \mathrm{hPa}$

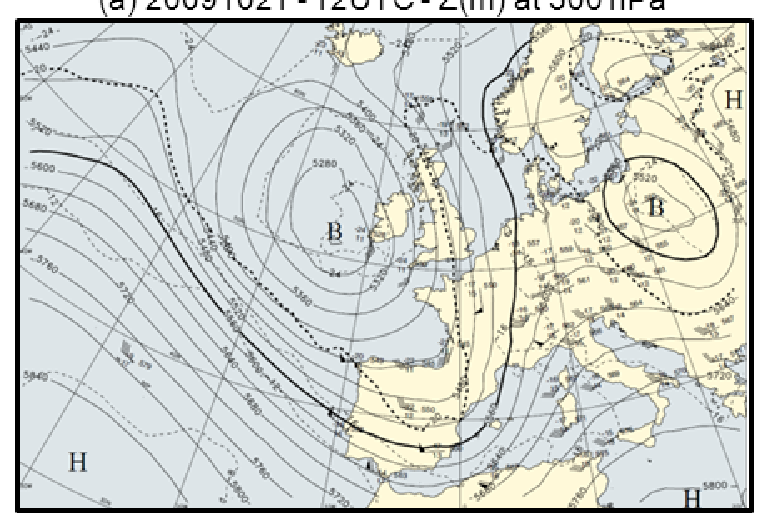

(b) 20091021 - 12UTC - Surface Pressure (hPa)

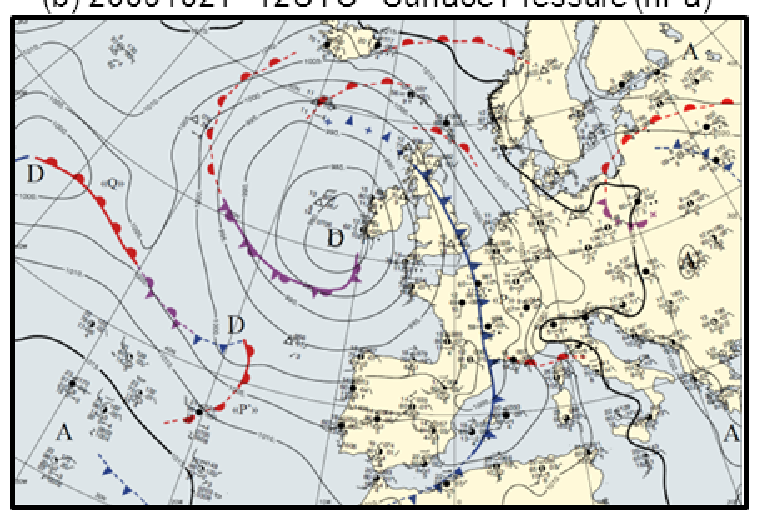

(c) $20091021-\mathrm{QPE}(\mathrm{mm})$

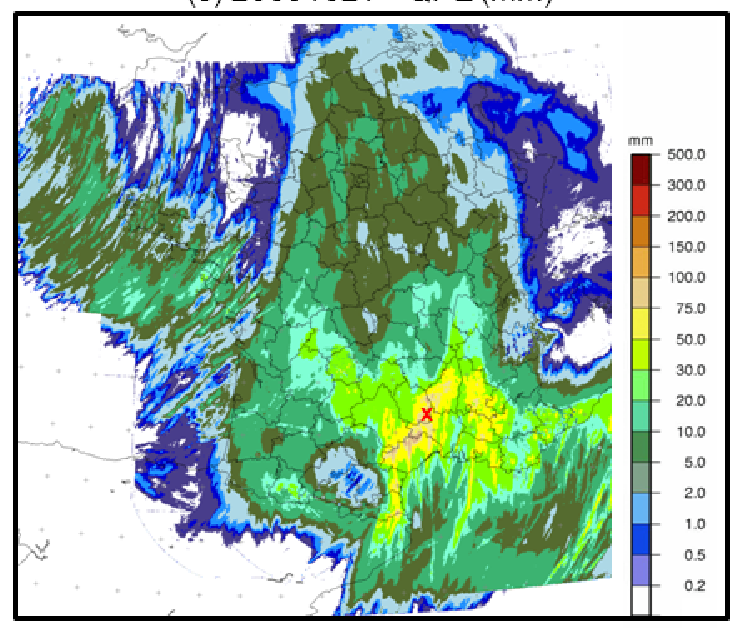

Figure 8: Overview of meteorological conditions on 21 October 2009. (a) Operational analysis of geopotential height at $500 \mathrm{hPa}$ valid at 12 UTC. (b) Operational surface analysis valid at 12 UTC. (c) 24-h accumulated precipitation (mm) over France starting at 00 UTC. Red cross in (c) indicate the city of Villefort. 

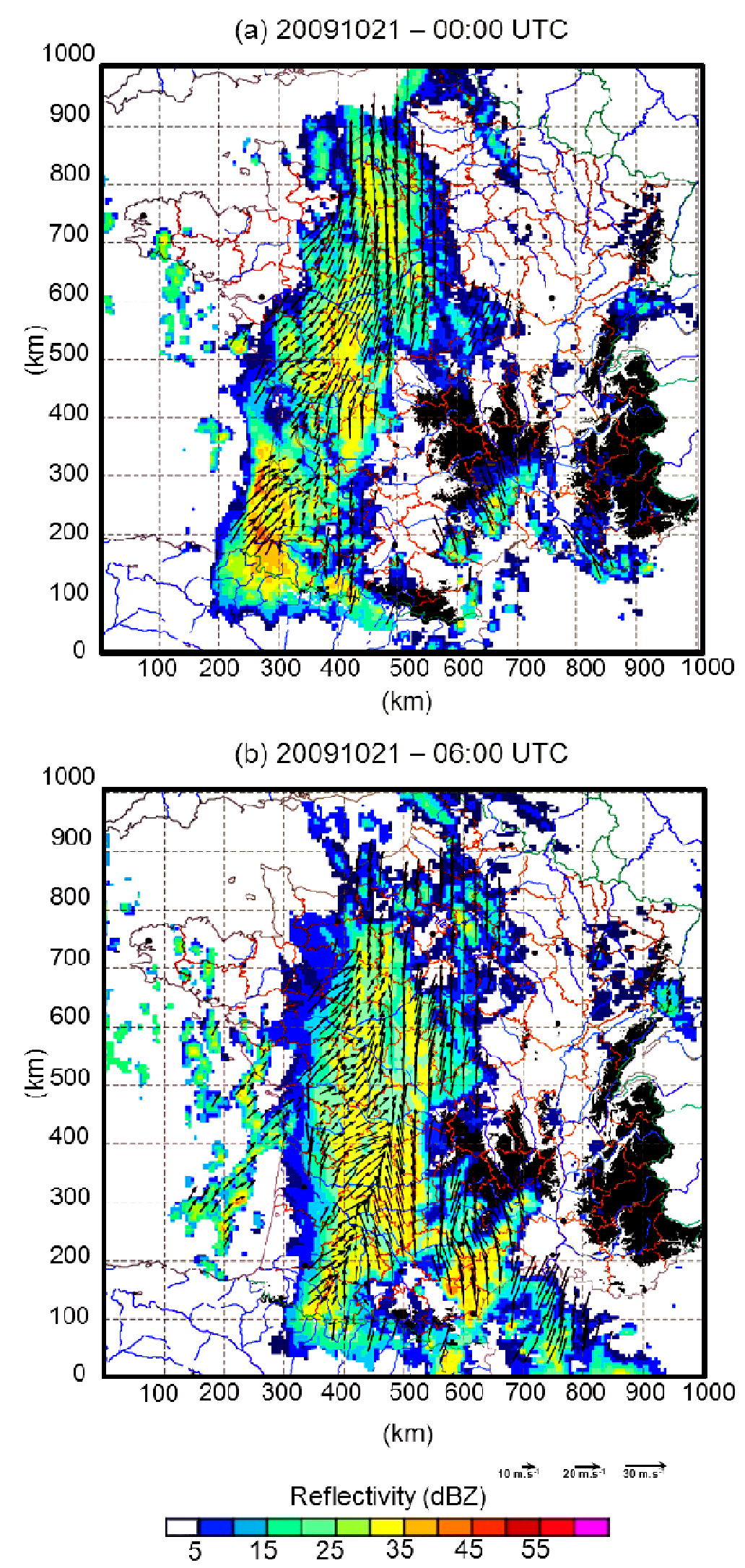

Figure 9: Multiple-Doppler analysis of radar data at $2 \mathrm{~km}$ AMSL within the $1000 \mathrm{x} 1000 \mathrm{~km}^{2}$ domain shown in Fig. 2 on 21 October 2009. Wind vectors superimposed on radar reflectivity (colour shading, dBZ) valid at (a) 0UTC, (b) 6UTC, (c) 12UTC and (d) 18UTC. Red solid lines show the location of cross-sections shown in Fig. 11. The white box in (c) indicates the display domain for Fig. 13. One in every sixth vector is plotted. 

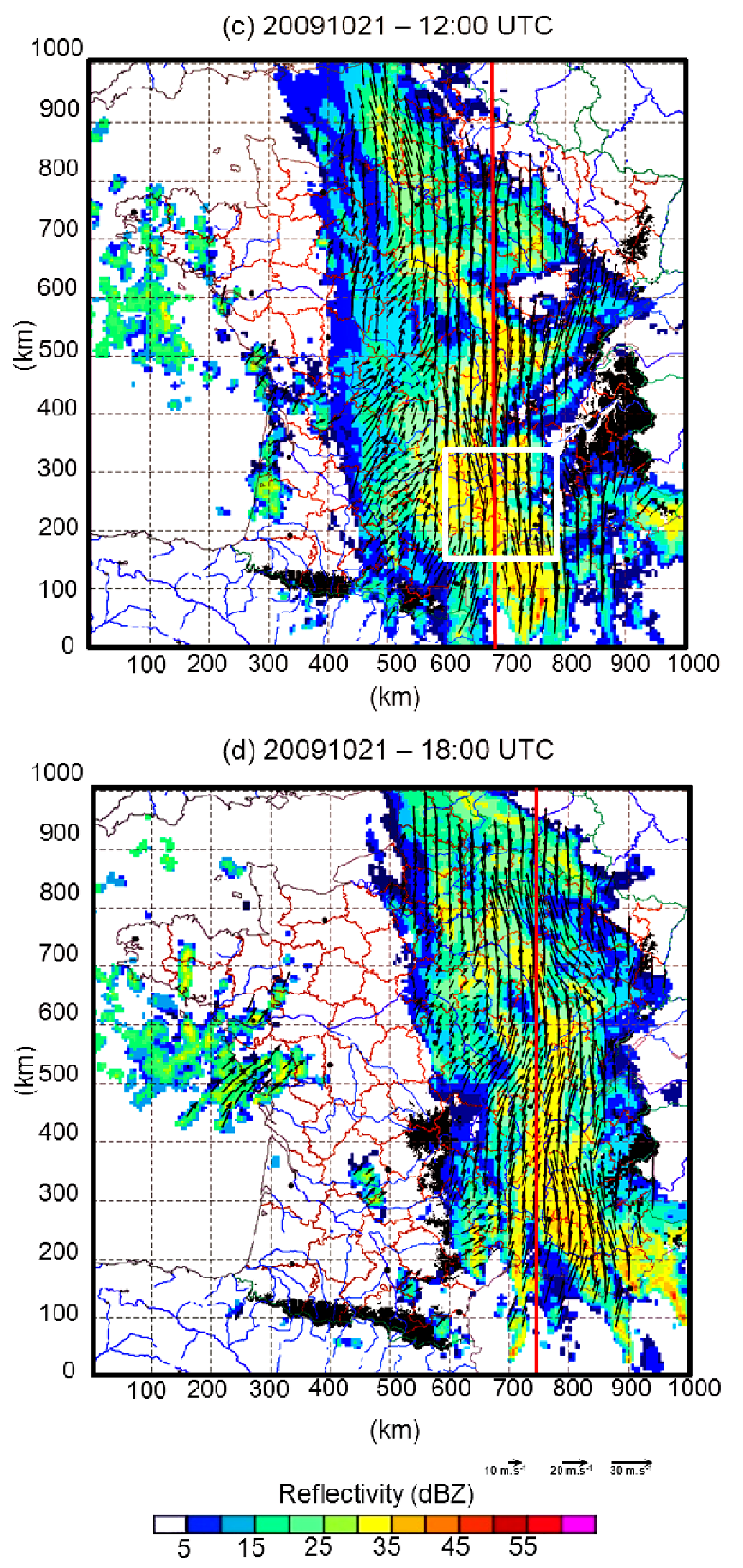

Figure 9: Ctnd 
(a) $20091021-12: 00$ UTC $-X=680 \mathrm{~km}$

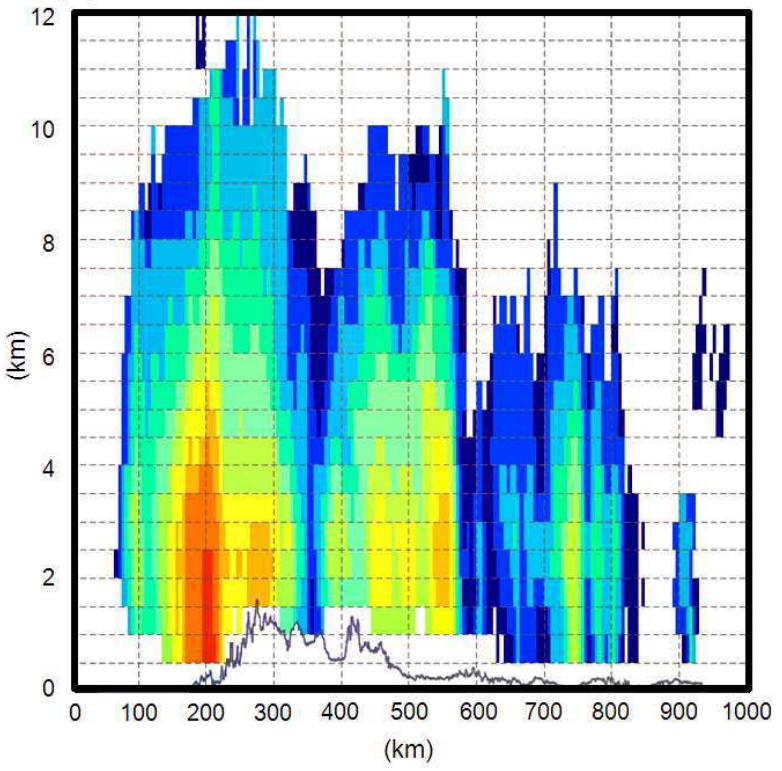

(b) $20091021-18: 00$ UTC - X = $745 \mathrm{~km}$

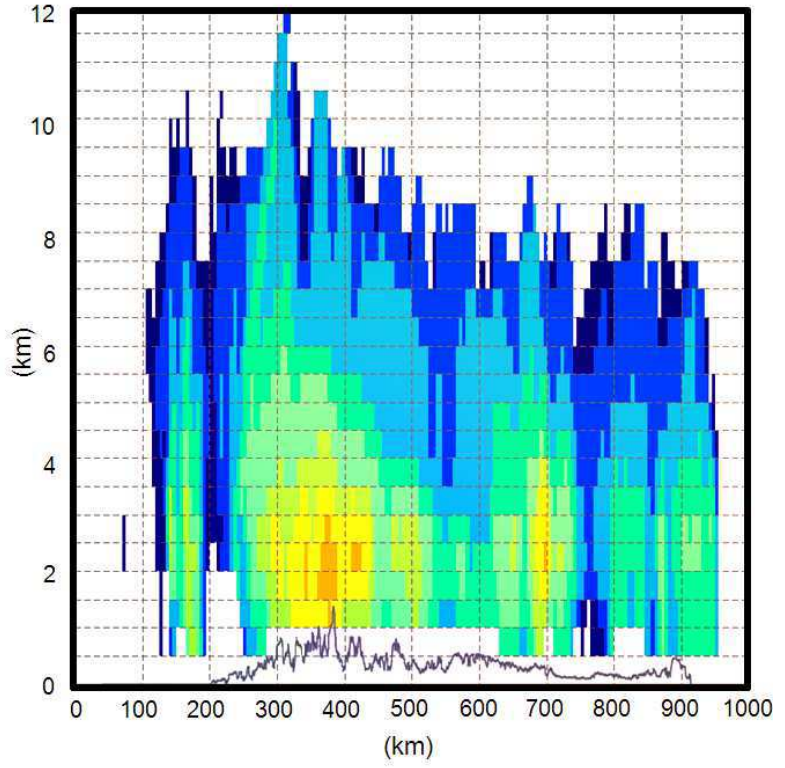

Reflectivity (dBZ)

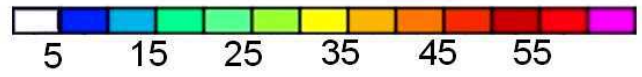

Figure 10: Vertical cross-sections of radar reflectivity (dBZ) along red lines shown in Fig. 10 based upon data collected at (a) 12 UTC and (b) 18 UTC, 21 October 2009. Outline of underlying terrain is indicated by a continuous medium-grey line. 
20091021 - 12:00 UTC - 1.5 km MSL
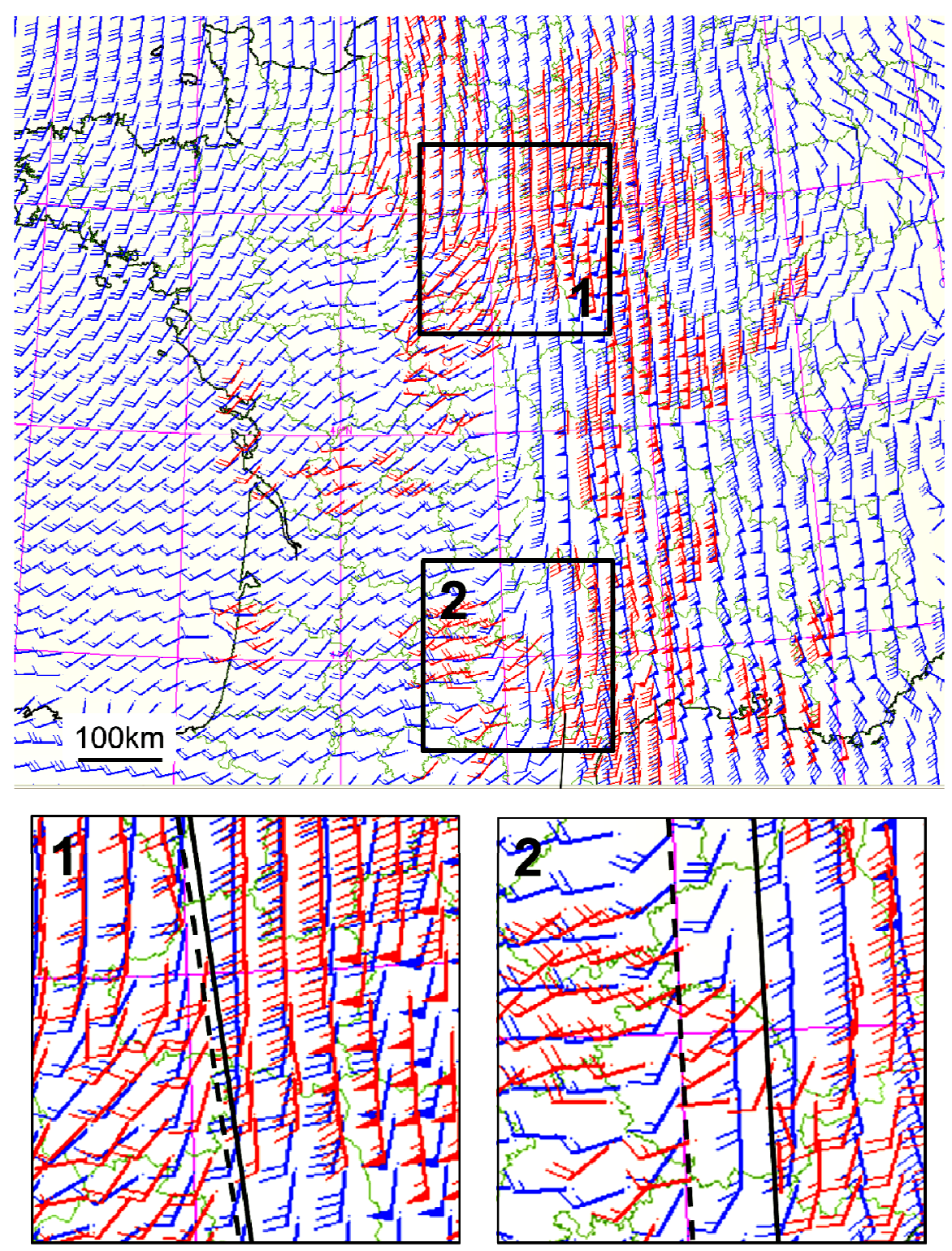

Figure 11: As in Fig. 7, but for 21 October 2009 at 12 UTC. Black plain (resp. dashed) line in inserts 1 and 2 shows the location of the surface cold front deduced from model (resp. radar) wind data. 

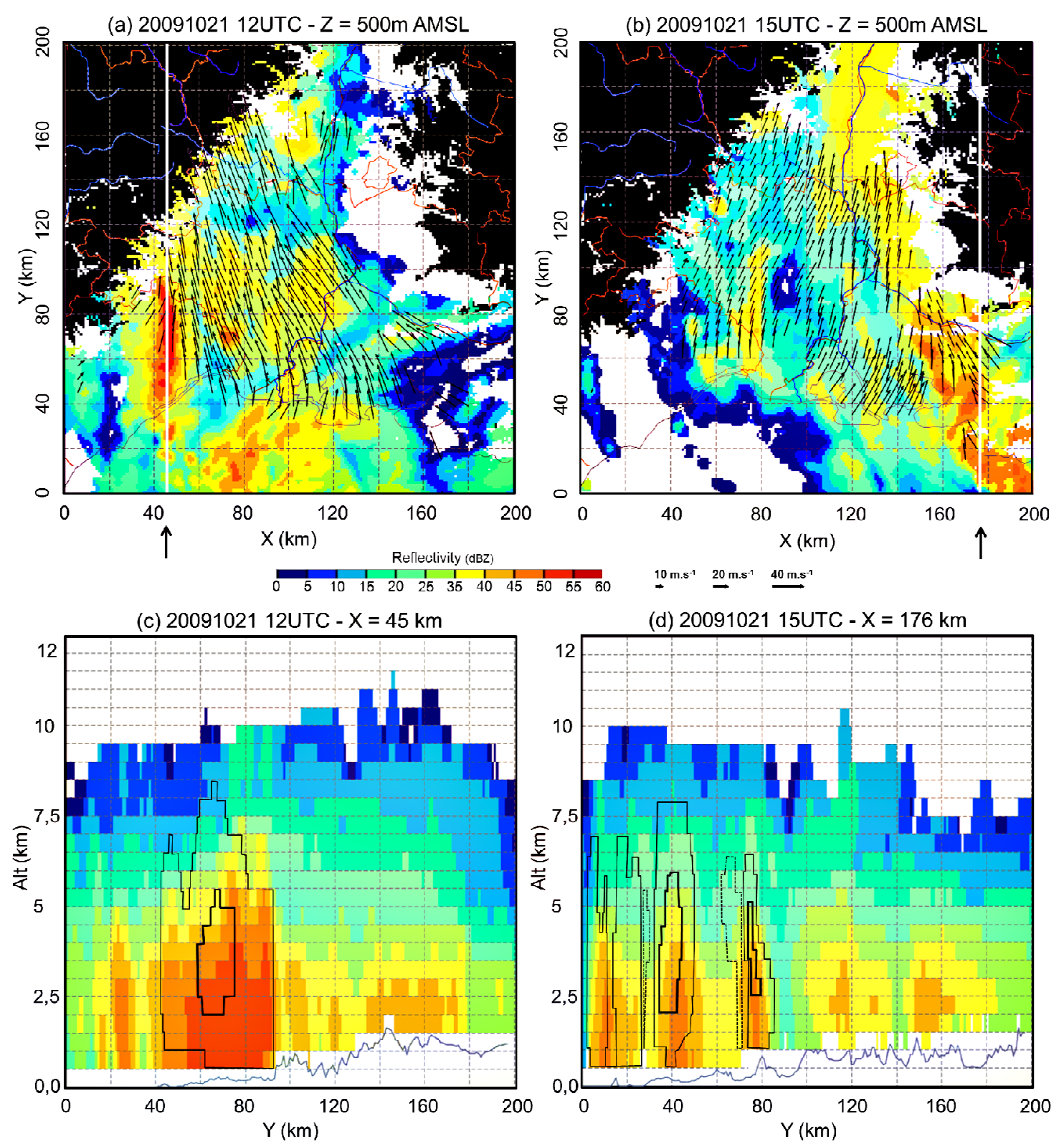

Figure 12: High horizontal resolution $\left(1 \mathrm{~km}^{2}\right)$ multiple-Doppler analysis of radar data on 21 October 2009, within the domain of $200 \mathrm{~km}$ x $200 \mathrm{~km}$ shown in Fig. 9c. Upper panels show radar reflectivity (dBZ, colour shaded) and wind vectors at 500m AMSL valid at (a) 12 UTC and (b) 15 UTC. One in every fifth vector is plotted. Lower panel show vertical cross-sections of reflectivity and vertical velocity at (c) 12 UTC and $x=45 \mathrm{~km}$ and (d) 15 UTC and $x=176$ $\mathrm{km}$. In (a-b), black shading indicates Massif Central (left hand side) and Alps (right hand side) mountain chains. White lines show locations of vertical cross-sections shown in (c-d). In (c-d) black contours show areas of vertical velocity higher than $1 \mathrm{~m} . \mathrm{s}^{-1}$ (plain) and $3 \mathrm{~m} . \mathrm{s}^{-1}$ (bold). Dashed line shows area of negative vertical velocity lower than $-1 \mathrm{~m} \cdot \mathrm{s}^{-1}$. Outline of underlying terrain is indicated by continuous medium-grey line. 
